\title{
Survival Motor Neuron Protein in Motor Neurons Determines Synaptic Integrity in Spinal Muscular Atrophy
}

\author{
Tara L. Martinez, ${ }^{1,3 \star}$ Lingling Kong, ${ }^{1 \star}$ Xueyong Wang, ${ }^{4}$ Melissa A. Osborne, ${ }^{5}$ Melissa E. Crowder, ${ }^{1}$ \\ James P. Van Meerbeke, ${ }^{1}$ Xixi Xu, ${ }^{1}$ Crystal Davis, ${ }^{5}$ Joe Wooley, ${ }^{1}$ David J. Goldhamer, ${ }^{6}$ Cathleen M. Lutz, ${ }^{5}$ Mark M. Rich, ${ }^{4}$ \\ and Charlotte J. Sumner ${ }^{1,2}$ \\ Departments of ${ }^{1}$ Neurology and ${ }^{2}$ Neuroscience, Johns Hopkins University, Baltimore, Maryland 21205, ${ }^{3}$ W. Harry Feinstone Department of Molecular \\ Microbiology and Immunology, Johns Hopkins Bloomberg School of Public Health, Baltimore, Maryland 21205, ${ }^{4}$ Departments of Neurology, Neuroscience, \\ Cell Biology and Physiology, Wright State University, Dayton, Ohio 45435, ${ }^{5}$ The Jackson Laboratory, Bar Harbor, Maine 04609, and ${ }^{6}$ Center for Regenerative \\ Biology, Department of Molecular and Cell Biology, University of Connecticut, Storrs, Connecticut 06269
}

The inherited motor neuron disease spinal muscular atrophy (SMA) is caused by deficient expression of survival motor neuron (SMN) protein and results in severe muscle weakness. In SMA mice, synaptic dysfunction of both neuromuscular junctions (NMJs) and central sensorimotor synapses precedes motor neuron cell death. To address whether this synaptic dysfunction is due to SMN deficiency in motor neurons, muscle, or both, we generated three lines of conditional SMA mice with tissue-specific increases in SMN expression. All three lines of mice showed increased survival, weights, and improved motor behavior. While increased SMN expression in motor neurons prevented synaptic dysfunction at the NMJ and restored motor neuron somal synapses, increased SMN expression in muscle did not affect synaptic function although it did improve myofiber size. Together these data indicate that both peripheral and central synaptic integrity are dependent on motor neurons in SMA, but SMN may have variable roles in the maintenance of these different synapses. At the NMJ, it functions at the presynaptic terminal in a cell-autonomous fashion, but may be necessary for retrograde trophic signaling to presynaptic inputs onto motor neurons. Importantly, SMN also appears to function in muscle growth and/or maintenance independent of motor neurons. Our data suggest that SMN plays distinct roles in muscle, NMJs, and motor neuron somal synapses and that restored function of SMN at all three sites will be necessary for full recovery of muscle power.

\section{Introduction}

The motor neuron disease spinal muscular atrophy (SMA) causes severe muscle weakness frequently leading to mortality in infancy (Dubowitz, 1995; Crawford, 2003). SMA is caused by homozygous mutation of the survival motor neuron 1 (SMN1) gene (Lefebvre et al., 1995), but all patients retain at least one copy of the SMN2 gene. Although a minority of transcripts derived from SMN2 are spliced to incorporate exon 7, most lack exon 7 and code for an unstable, truncated protein (Lorson et al., 1998, 1999; Monani et al., 1999). Thus, insufficient expression of full-length

Received Jan. 14, 2012; revised May 2, 2012; accepted May 8, 2012.

Author contributions: T.L.M., L.K., M.A.O., D.J.G., C.M.L., M.M.R., and C.J.S. designed research; T.L.M., L.K., X.W., M.A.O., M.E.C., J.P.V.M., X.X., C.D., J.W., and M.M.R. performed research;T.L.M., L.K., X.W., M.A.O., J.P.V.M., M.M.R., and C.J.S. analyzed data; T.L.M., L.K., M.M.R., and C.J.S. wrote the paper.

C.J.S. was supported by NINDS Grant R01NS062869, Howard Hughes Medical Institute Physician Scientist Award, and the Spinal Muscular Atrophy Research Team. M.M.R. was supported by NINDS Grant P01NS057228. D.J.G. was supported by National Institute of Arthritis and Musculoskeletal and Skin Diseases Grant R01AR052777. Funding for the work at Jackson Laboratory was supported by the Spinal Muscular Atrophy Foundation. We thank Francisco Alvarez for advice regarding EM, John Thorndyke, Heloisa Carvalho, Lauren Wu, Diana Villanueva, Emily Bergbower, Kristen Klepac, and Emmanuel Ohuabunwa for technical help, and Carol Cooke and Michael McCaffery for EM assistance.

*T.L.M. and L.K. contributed equally to this work.

The authors declare no competing financial interests.

Correspondence should be addressed to Charlotte J. Sumner, 855 North Wolfe Street, Rangos 248, Baltimore, MD 21287. E-mail: csumner1@jhmi.edu.

DOI:10.1523/JNEUROSCI.0204-12.2012

Copyright $\odot 2012$ the authors $\quad 0270-6474 / 12 / 328703-13 \$ 15.00 / 0$
SMN protein causes SMA with disease severity correlating inversely with SMN2 copy number (Feldkötter et al., 2002). The ubiquitously expressed SMN protein mediates the assembly of small nuclear ribonuclear proteins (snRNPs), but may also enable axonal mRNA transport and local mRNA processing (Burghes and Beattie, 2009).

SMA mouse models recapitulate key aspects of severe SMA including severe weakness and early death (Le et al., 2005; Park et al., 2010a). Nonetheless, SMA mice show surprisingly limited muscle denervation and motor neuron loss overall, although particular muscle groups and motor neuron subsets are more vulnerable than others (Kong et al., 2009; Mentis et al., 2011; Ling et al., 2012). Early symptomatic stages of disease are characterized by morphological and functional abnormalities of synapses, affecting both neuromuscular junctions (NMJs) (Kariya et al., 2008; Murray et al., 2008; Kong et al., 2009; Ling et al., 2010; Ruiz et al., 2010; Dachs et al., 2011; Lee et al., 2011) and synaptic inputs to motor neurons in the spinal cord (Ling et al., 2010; Mentis et al., 2011). These abnormalities are associated with impaired maturation of NMJ endplates and myofibers (Kong et al., 2009; Lee et al., 2011) as well as loss of vesicular transporter 1-positive (VGluT1+) inputs to motor neurons (Ling et al., 2010; Park et al., 2010b; Mentis et al., 2011). Synaptic abnormalities precede motor neuron death and this period of synaptic dysfunction may define a window of disease reversibility and therapeutic responsiveness in SMA. Nonetheless, it remains unknown whether these 
abnormalities are dependent on reduced SMN expression in presynaptic or postsynaptic sides of peripheral and/or central synapses and this has important implications for sites of therapeutics delivery in SMA.

To understand the cellular determinants of synaptic function in SMA, we generated three lines of SMA mice expressing increased levels of SMN principally in either motor neurons or muscle. We show that NMJ synaptic function and motor neuron somal synapses are substantially improved by increased SMN expression in motor neurons, but not by increased SMN expression in muscle suggesting that synaptic function and connectivity are largely determined by motor neurons in SMA. SMN also appears to have a role in growth of muscle that is independent of its effect on motor neuron synaptic function. Our findings suggest that SMN has variable roles at distinct sites within the motor unit.

\section{Materials and Methods}

Mice. All experiments were performed in accordance with the National Institutes of Health Guide for the Care and Use of Laboratory Animals, and were approved by Johns Hopkins University, Wright State University, and Jackson Laboratory Animal Care Committees. ChAT ${ }^{\text {Cre }}$ (Jackson Laboratory Stock \#006410), MyoD ${ }^{i C r e}$ (Jackson Laboratory Stock $\# 014140$ ) (Kanisicak et al., 2009), and Myf5 ${ }^{\text {Cre }}$ (Jackson Laboratory Stock \#007893) (Tallquist et al., 2000) were bred to a lacZ-Cre reporter strain, B6.129S4-Gt(ROSA)26Sortm1Sor/J (Jackson Laboratory Stock \# 003474) (Soriano, 1999) to analyze Cre expression patterns in $15.5 \mathrm{~d}$ postconception embryos (E15.5) and postnatal day 7 (P7) pups. MyoD ${ }^{i C r e}$ is an optimized Cre recombinase that has high recombination efficiency in myoblasts and satellite precursor cells of the embryo (Kanisicak et al., 2009; Yamamoto et al., 2009).

SMA mice expressing a Smn Cre-inducible allele $\left(S m n^{\text {Res }}\right)$ (Lutz et al., 2011 ) and 2 copies of $S M N 2$ and $S M N \Delta 7$ alleles $\left(\mathrm{Smn}^{\text {Res }} / \mathrm{SMN} 2^{+/+}\right.$/ $\operatorname{SMN} \Delta 7^{++)}$were bred to $C h A T^{C r e}, M y o D^{i C r e}$, or $M y f 5^{C r e}$ expressing mice. Cre - SMA mice were those carrying the inducible Smn allele in a homozygous state $\left(S m n^{\text {Res/Res }} / S M N 2^{+/+} / S M N \Delta 7^{+/+}\right)$in the absence of Cre, Cre + SMA mice were those carrying the inducible $S m n$ allele in a homozygous state $\left(S m n^{\text {Res/Res }} / S M N 2^{+/+} / S M N \Delta 7^{+/+}\right)$in the presence of Cre, heterozygous (Het) mice were those carrying the inducible $S m n$ allele in a heterozygous state $\left(S m n^{\text {Res/+}} / S M N 2^{+/+} / S M N \Delta 7^{+/+}\right)$in the presence of Cre, and wild-type (WT) mice were those homozygous for the wild-type allele $\left(S m n^{+/+} / S M N 2^{+/+} / S M N \Delta 7^{+/+}\right)$in the absence of Cre.

Genotyping. Mice were genotyped by PCR of tail DNA as previously reported (Avila et al., 2007). To detect the uninverted $S m n^{\text {Res }}$ allele, the following primers were used: MUT-F: 5'-GGCAGTTTTAGACTCATC ATGTATCTG-3' and MUT-R: 5'-ACTTATGGAGATCCCTCGAGATAA C-3' yielding a 103 base pair product. To detect the inverted form of the $S m n^{\text {Res }}$ allele the following primers were used INV-F: $5^{\prime}$-GTTTTAGACT

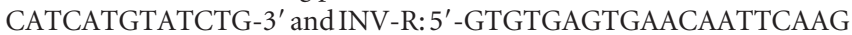
CC-3' yielding a 190 base pair inverted product and/or a 143 base pair endogenous product. To determine zygosity when necessary the following primers were used to detect the murine endogenous $S m n 1$ locus: WT-F: 5' -TGGGAGTCCATCCATCCTAAGTC-3' and WT-R: 5' -GCTA AGAAAATGACAATTGCACATTTG-3' yielding a 143 base pair product. To detect the presence of the Cre allele in the ChAT ${ }^{\text {Cre }}$ mice the following primers were used: ChAT Ires WT-F: 5'-GTTTGCAGAAGC GGTGGG-3', ChAT Ires WT-R: 5'-AGATAGATA ATGAGAGGCTC$3^{\prime}$, and ChAT Cre-R: $5^{\prime}$-CCTTCTATCGCCTTCTTGACG-3' ${ }^{\prime}$. To detect the Cre allele in the $M y f 5^{C r e}$ mice the following primers were used: Myf5 WT-F: 5'-CGTAGACGCCTGAAGAAGGTCAACCA-3', Myf5 WT-R: 5' CACATTAGAAAACCTGCCAACACC-3', and Myf5 Cre-R: 5'-ACGAAG TTATTAGGTCCCTCGAC- $3^{\prime}$. To detect Cre in $M y o D^{i C r e}$ mice the following primers were used: MyoD WT-F: 5'-CTAGGCCACAGAATTGAAAG ATCT-3', MyoD WT-R: 5'-GTAGGTGGAAATTCTAGCATCATCC-3', MyoD Cre-F: 5'-GCGGATCCGAATTCGAAGTTCC-3', and MyoD Cre-R: 5'-TGGGTC-TCCAAAGCGACTCC-3'.
Phenotypic assessment of mice. Daily weights were measured starting from the day of birth (P1). The average value of two trials of righting time was determined starting on P1 with a maximal time of $30 \mathrm{~s}$ per trial as previously described (Avila et al., 2007). The hind-limb suspension test was performed between $\mathrm{P} 2$ and P12 by suspending the mouse from the hind-limbs on the edge of a $50 \mathrm{ml}$ conical tube as previously described by El-Khodor et al. (2008). Average position score, total number of pulls, and total latency to fall time (maximum $30 \mathrm{~s}$ ) during 2 trials were determined. A composite score of this test was used (Heier et al., 2010). Ambulation index was performed between P13 and P23. The total time upright, numbers of $5.5 \times 5.5 \mathrm{~cm}$ grid squares crossed, and number of rearings onto the hindlimbs were determined during two $60 \mathrm{~s}$ trials.

Quantitative reverse transcription PCR. RNA was isolated from tissues (whole spinal cord, quadriceps muscle, or pooled lumbar level 3-5 dorsal root ganglia (DRGs) using TRIzol reagent (Invitrogen) and converted to cDNA as previously described (Avila et al., 2007). Primers (SMN6m8h) to amplify the shortened cDNA product arising from the uninverted and inverted hybrid rescue $S m n$ allele were: Exon 6m8h:5' -GGCTACCACACTGG CTACTATATGG-3', Exon8hR: 5'-GCTTCACATTCCAGATCTGTCT-3', and Exon8hprobe: 6FamCATAGAGCAGCT CTA AATGACACCACTAAA GAAtamra. Primers (SMN67m8h) used to amplify the full-length cDNA product arising from the inverted Smn allele were: Exon67F: 5'-GCTACT ATATGGGTTTCAGACAAAATAAAA-3', Exon8hR: 5'-GCTTCAC ATT CCAGATCTGTCT-3', and Exon8hprobe: 6FamCATAGAGCAGCTCTA AATGACACCACTAAAGAAtamra. Primers localized to the mouse Smn exons 1 and 2 region (SMN12m) were used as an endogenous control: Exon1mF:5'-GCTCCGAGCAGGAAGATACG-3',Exon2mR:5'-CAATGC TGTATCATCCCAAATGTC-3', and Exon 1 mprobe: 6FamCTGTTC CGG CGT GGC ACC Gtamra. Reactions were run in triplicate using the ABI Prism 7900 Sequence Detector System as previously described (Avila et al., 2007).

Western blot. Spinal cord or quadriceps muscle tissues were homogenized in RIPA buffer (Sigma) with protease inhibitors (Roche) and sonicated. Approximately $30 \mu \mathrm{g}$ of spinal cord or $60 \mu \mathrm{g}$ of muscle total protein lysate was resolved on $12 \%$ Tris-Glycine gels and transferred to PVDF membranes (Invitrogen). Primary antibodies used included mouse anti-SMN (1:2500; BD Transduction Laboratories), mouse anti- $\beta$-actin clone AC-15 (1:10,000; Sigma) and mouse anti-glyceraldehyde 3-phosphate dehydrogenase (GAPDH) clone 6C-5 (1:5000; Abcam) antibodies followed by a donkey anti-mouse-HRP-conjugated secondary antibody $(1: 10,000$; GE Healthcare). Densitometry measures of full-length SMN protein levels were performed using NIH Image software.

Histology. For assessing patterns of Cre expression, pregnant females were killed, the uterus dissected, and extra-embryonic tissues removed in cold PBS. Embryos were individually frozen in optimal cutting temperature (O.C.T.) compound on dry ice. A small piece of tissue was collected from each embryo before freezing to confirm the genotype. For P7 tissues, mice were killed and brain, eye, heart, lungs, skeletal muscle (iliopsoas, tibialis anterior, and quadriceps), skin, kidney, spleen, pancreas, liver, reproductive organs, bladder, intestine, brown fat, femur, and spinal cord (cervical, thoracic, and lumbar regions) were collected and frozen in O.C.T. compound on dry ice immediately after collection. Frozen embryos and tissues were cryo-sectioned, stained with X-gal overnight at $37^{\circ} \mathrm{C}$, and counter-stained with Nuclear Fast Red. LacZ expression in skeletal muscle was quantified using CellProfiler imaging software. Images of stained muscle sections from 2 to 3 mice per strain were analyzed for color differences; in this case blue (lacZ/ $\beta$-gal) and red (Fast Red). The software analyzed each tissue section to measure total area of tissue in pixels as well as the specific area expressing homogeneous $\beta$-gal staining.

For muscle and myofiber quantification, dissected muscle tissues were flash frozen in liquid nitrogen. Cryostat sections $(30 \mu \mathrm{m})$ were cut and stained with hematoxylin and eosin (H\&E). Myofiber morphology and diameter were assessed using a Zeiss AxioImager Z1 microscope. Myofiber diameters were determined by measuring the longest aspect of the shortest axis using Zeiss AxioVision 4.6 software.

Immunohistochemistry. Mice were transcardially perfused with $4 \%$ paraformaldehyde (PFA) and postfixed in PFA for $24 \mathrm{~h}$. Spinal lumbar segment 1 (L1) was dissected from the spinal cord and serial transverse sections ( $70 \mu \mathrm{m}$ thick) were cut using a Leica Vibratome. Sections were 
stained using polyclonal goat anti-ChAT (1:100; Millipore), chicken anti- $\beta$-galactosidase (1:2000; Abcam), or anti-rabbit VGluT1 (1:1000; Synaptic Systems) antibodies, followed by the appropriate secondary antibodies (1:200; Jackson ImmunoResearch). Images were taken at 1 $\mu \mathrm{m}$ intervals using a Zeiss LSM Meta 510 confocal microscope. Only ChAT + motor neurons containing a visible nucleus were counted to avoid double counting motor neurons from adjoining sections.

NMJs were examined in serial muscle sections from the tibialis anterior (TA) and splenius capitis muscles. Mice were transcardially perfused with $4 \%$ PFA and muscles were isolated, postfixed in 4\% PFA for $24 \mathrm{~h}$, cryoprotected in $30 \%$ sucrose for $24 \mathrm{~h}$, and cut longitudinally on a cryostat at $60 \mu \mathrm{m}$ thickness. Tissue sections were labeled using monoclonal mouse anti-SMI 312 (1:1000; Covance) and polyclonal rabbit-antisynaptophysin (1:500; Invitrogen) antibodies, followed by FITC goat anti-mouse IgG1 (1:200; Jackson Immunoresearch Laboratories), Alexa Fluor 633-conjugated goat anti-rabbit secondary antibody (1:1000; Invitrogen) as well as $\alpha$-Bungarotoxin Alexafluor-555 (1:500; Invitrogen). Images were obtained using a Zeiss AxioImager Z1 microscope. Z-stack projections were made from serial scanning every $1 \mu \mathrm{m}$ to reconstruct the NMJ. Innervation status was examined by classifying individual NMJs into one of three groups: $<25 \%, 25-75 \%$, or $>75 \%$ occupancy of an $\alpha$-bungarotoxin-labeled endplate by synaptophysin-stained presynaptic terminal. Presynaptic neurofilament (NF) accumulation was defined as NF occupying $\geq 1 / 4$ of the postsynaptic terminal area. NMJ size was determined by measuring the area of $\alpha$-bungarotoxin staining using Zeiss AxioVision 4.6 software.

Electron microscopy. Mice were transcardially perfused and postfixed for $24 \mathrm{~h}$ with $3 \%$ glutaraldehyde/4\% PFA and spinal cords were then dissected. The L1 segment was rinsed with 0.1 m Sorensen's buffer, postfixed using $2 \%$ osmium tetroxide, dehydrated in serial alcohol dilutions, embedded in propylene oxide and EMbed 812 plastic (Electron Microscopy Sciences), and placed in an oven to harden into capsule form. Thick sections $(1 \mu \mathrm{m})$ were cut on an ultramicrotome and multiple sections were placed on Superfrost slides, dried, stained with toluidine blue, and viewed by light microscopy. Thin sections were cut at $60-90 \mathrm{~nm}$, placed on Formvar grids, and viewed using Tecnai 12 (FEI) and Libra 120 (Zeiss) electron microscopes. Motor neuron somata in the ventral horn area containing a visible central nucleolus and rich cytoplasm were identified and all synapses contacting the surface of these somata were then imaged. At least three animals were used for each group from the ChATCre SMA line and at least four motor neurons per animal were counted for the number of boutons, number of synapses [defined as boutons juxtaposed to an electron dense postsynaptic density (PSD)], PSD length, and synaptic density per synapse at $23,000 \times$ magnification or higher using the TEM software. Readily releasable pools were defined as those vesicles within $100 \mathrm{~nm}$ distance from the PSD area.

Electrophysiological recordings from NMJs. Physiology was performed on P10-P14 mouse NMJs from the TA muscle as previously described (Kong et al., 2009). Briefly, muscle was perfused with Ringer solution containing (in millimoles per liter): $\mathrm{NaCl}, 118 ; \mathrm{KCl}, 3.5 ; \mathrm{CaCl}_{2}, 2$; $\mathrm{MgSO}_{4}, 0.7 ; \mathrm{NaHCO}_{3}, 26.2 ; \mathrm{NaH}_{2} \mathrm{PO}_{4}, 1.7$; glucose, 5.5 (pH 7.3-7.4, $20-22^{\circ} \mathrm{C}$ ) equilibrated with $95 \% \mathrm{O}_{2}$ and $5 \% \mathrm{CO}_{2}$. All NMJs were imaged by staining with 4-Di-2-ASP and impaled within $100 \mu \mathrm{m}$ of the endplate. Muscle fibers were crushed away from the endplate band and voltage clamped to $-45 \mathrm{mV}$. Quantal content was determined directly by dividing evoked endplate current (EPC) amplitude by the average miniature endplate current (MEPC) amplitude for a given NMJ. Repetitive stimulation was given by applying a $50 \mathrm{~Hz}$ train of 10 pulses.

Statistics. All data are expressed as mean \pm SEM. Morphological and biochemical data were analyzed using Excel and Statistica software. Statistical significance was determined using either Student's $t$ test or a two-way ANOVA. Physiological data were analyzed using Student's $t$ test or a nested ANOVA using Systat (Cranes Software).

\section{Results}

SMN is expressed in a tissue-specific manner in conditional SMA mice

To generate SMA mice with increased SMN expression selectively in motor neurons or muscle, we used SMA mice that express a
Cre-inducible Smn allele $\left(S m n^{\text {Res }}\right)$ (Lutz et al., 2011) together with mice expressing Cre recombinase under the control of either the ChAT promoter, the MyoD promoter (Kanisicak et al., 2009), or the Myf5 promoter (Tallquist et al., 2000). ChAT is expressed in motor neurons in the ventral horn of the spinal cord starting at E12.5 (Phelps et al., 1991). Subsequently, ChAT slowly increases in expression until birth and then more rapidly increases postnatally until adulthood (Lönnerberg et al., 1995). MyoD and Myf5 are muscle-specific transcription factors expressed at high levels in muscle precursor cells and myofibers starting at E9.75 and E8, respectively (Ott et al., 1991; Kanisicak et al., 2009).

We examined the spatial and temporal pattern of Cre expression by breeding each Cre line to a Cre-dependent lacZ reporter line and by performing X-gal staining to detect $\beta$-gal expression in E15.5 whole embryos and dissected P7 tissues (Fig. $1 A, B$ ). As has been previously shown at multiple embryonic and postnatal time points (see http://cre.jax.org/Chat/Chat-CreNanozoomer. html), $\beta$-gal expression in P7 ChAT ${ }^{\text {Cre }}$ mice was restricted to large neurons in the ventral horn of the spinal cord (Fig. $1 B$ ) and some neurons of the brainstem and cortex (data not shown). Expression was absent from muscle (Fig. $1 B$ ), heart, liver, other internal organs, bone, brown fat, and skin (data not shown). In $M y o D^{i C r e}$ embryos, $\beta$-gal expression was evident in skeletal muscles including those around the vertebrae, ribs, and sternum and in the diaphragm and limb muscles (Fig. $1 A$ ) as previously reported, but not in the neural tube (Kanisicak et al., 2009; Yamamoto et al., 2009). In P7 mice, robust staining was present in myofibers, but not in spinal cord (Fig. $1 B$ ), brain, heart, or other internal organs (data not shown). Embryonic $M y f 5^{C r e}$ mice showed a similar pattern of muscle staining to $M y o D^{i C r e}$ mice, but also some foci of staining in the neural tube (Fig. $1 A$ ). At P7, robust staining was evident in muscle, but low levels of staining were also evident in the ventral horn of the spinal cord (Fig. $1 B$ ). Robust staining was also seen in dorsal root ganglion (DRG) neurons (Fig. $1 B$ ), brown fat, and skin (data not shown). Expression of Cre in both the neural tube and DRG in this line of $M y f 5^{C r e}$ mice has been previously reported (Gensch et al., 2008). High-power examination of P7 quadriceps muscle cross sections revealed strong, diffuse lacZ staining of many myofibers that occupied $31.8 \pm$ $0.069 \%$ and $39.1 \pm 0.036 \%$ of the total muscle cross sectional area in $M y o D^{i C r e}$ and $M y f 5^{C r e}$ mice, respectively. In addition, punctate lacZ staining was evident in most other myofibers.

To further investigate whether visible lacZ expression in the spinal cord was present specifically in motor neurons, we performed immunohistochemistry (IHC) for lacZ and ChAT on P7 spinal cords. This confirmed $\beta$-gal expression specifically in ChAT-positive ventral horn motor neurons in ChAT ${ }^{\text {Cre }}$ and $M y f 5^{C r e}$ mice, but not in $M y o D^{i C r e}$ mice (Fig. $1 C$ ). Together, these data indicate that Cre expression is limited to motor neurons in the spinal cord in $C h A T^{\mathrm{Cre}}$ mice and to muscle in $M y o D^{i C r e}$ mice, but is present in muscle, motor neurons, and DRG neurons in Myf5 ${ }^{\text {Cre }}$ mice.

The Cre-inducible $S m n$ allele $\left(S m n^{\text {Res }}\right)$ contains a switch cassette flanked by loxP sites in opposing orientation, which was introduced into the endogenous mouse gene (Lutz et al., 2011). The switch cassette contains human exon 7 sequence in the correct orientation and the mouse exon 7 sequence in the opposite and thus translationally silent orientation. In the absence of Cre, this hybrid allele consists of upstream mouse Smn sequence (exons 1-6) together with human SMN2 exons 7 and 8 sequence and produces predominantly truncated SMN transcripts (SMN 68) (Fig. 2A). Following Cre-mediated genomic recombination, human SMN2 exon 7 sequence is replaced by mouse Smn exon 7 
sequence and predominantly full-length SMN transcripts (SMN 678) are produced (Fig. 2A). SMA mice expressing this allele together with Cre recombinase expressed either embryonically or early postnatally in all tissues have increased SMN expression and marked amelioration of the SMA phenotype (Lutz et al., 2011). After crossing $S m n^{R e s}$ SMA mice to each of the tissuespecific Cre-expressing lines of mice, we evaluated the expression patterns of truncated and full-length hybrid SMN transcripts in spinal cord and muscle tissues isolated at P10 by quantitative reverse transcription PCR (qRT-PCR). Primers were designed that are specific for mouse exon 6 and human exon 8 (SMN6m8h) and they detected both truncated (SMN 68) and full-length hybrid SMN transcripts (SMN678). Primers specific for mouse exon 6 , mouse exon 7 , and human exon 8 (SMN67m8-h) detected only fulllength hybrid transcripts (SMN 678) (Fig. $2 A)$. Primers specific for the mouse exons 1-2 (SMN12m) were used as an endogenous control (Fig. 2A) and all data were normalized to the transcript levels present in a $M y f 5^{C r e+}$ Het mouse muscle (this calibrator sample was set to 1 ). The SMN $6 \mathrm{~m} 8 \mathrm{~h}$ primers detected SMN 68 and/or SMN 678 hybrid transcript expression in both spinal cord and muscle in Cre - and Cre+ SMA mice homozygous for Smn $n^{\text {Res }}$ (Fig. 2A). Heterozygous mice expressing one copy of $S m n^{\text {Res }}$ showed approximately half the expression of the hybrid transcripts and WT mice, which do not have the $S m n^{\text {Res }}$ allele, showed no expression (Fig. 2 B). The SMN67m8h primers that amplify only SMN678 showed that this transcript is expressed in muscle only in $\mathrm{MyoD} \mathrm{irre}^{\mathrm{C}}$ and $\mathrm{Myf5} 5^{\mathrm{Cre}+}$ Het and Myo$\mathrm{D}^{i \mathrm{Cre+}}$ and $\mathrm{Myf5} 5^{\mathrm{Cre}+}$ SMA mice (Fig. 2C). Comparably lower levels of SMN 678 transcript were evident in spinal cord of ChAT ${ }^{\mathrm{Cre}+}$ Het and ChAT ${ }^{\mathrm{Cre}+}$ SMA mice. This relatively low level of expression detected in spinal cord is expected given that SMN rescue is specific to motor neurons, which constitute only a small fraction of total spinal cord tissue. A very low level of SMN 678 was also detectable in $M y f 5^{\text {Cre }}+$ SMA spinal cord, but not in $M y o D^{i C r e+}$ SMA spinal cord.

We also examined P10 tissues for corresponding changes in SMN protein expression (Fig. 2D,E). Not unexpectedly, given the modest increase of SMN 678 transcript expression, there was no appreciable increase in full-length SMN protein expression in the spinal cord of ChAT ${ }^{\text {Cre }}+$ SMA mice by Western blot. In contrast, $\mathrm{MyoD}^{i \mathrm{Cre}+}$ and $\mathrm{Myf5} 5^{\mathrm{Cre}+}$ SMA mice both
A

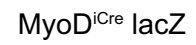

Myf5 $^{\text {Cre }}$ lacZ

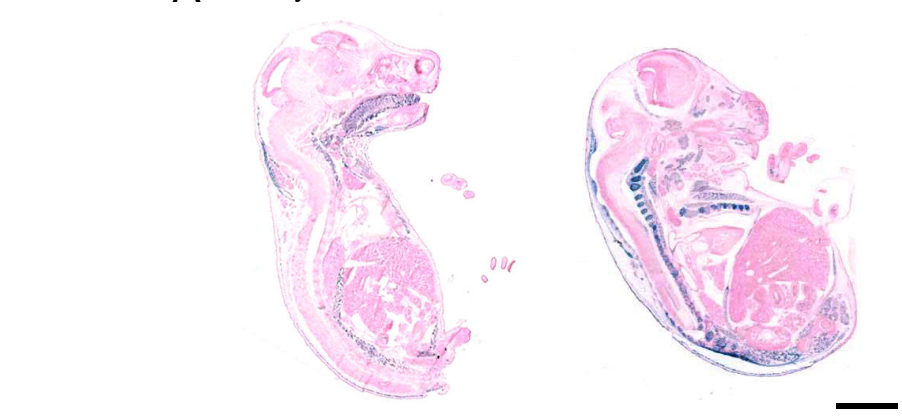

B
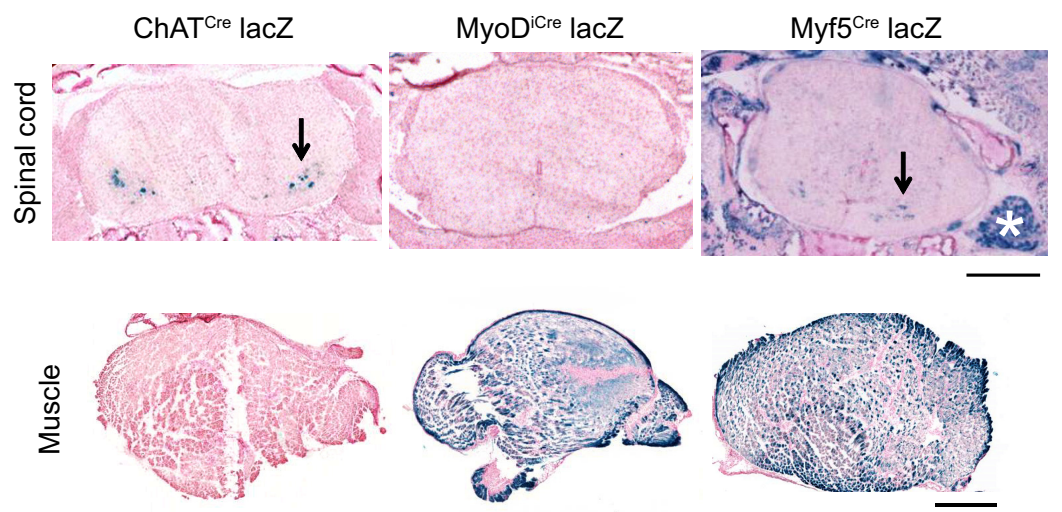

C
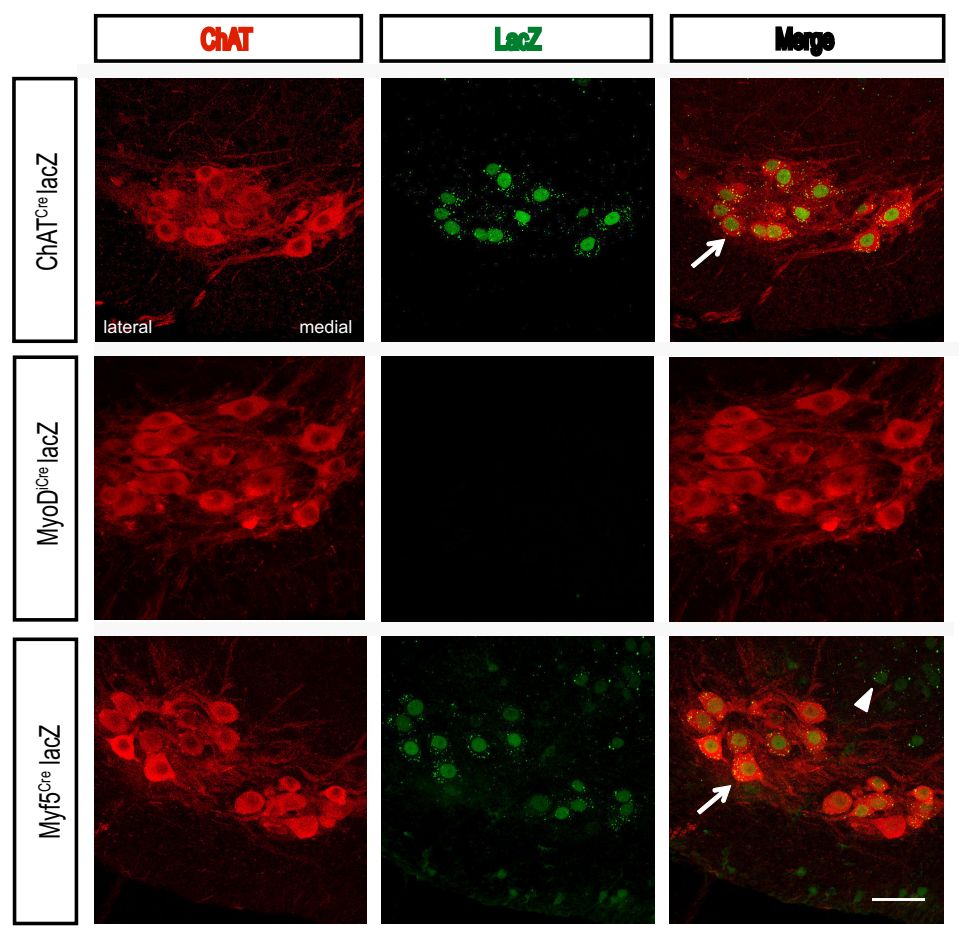

Figure 1. Cre is expressed in tissue-specific patterns in $C h A T^{C r e}, M y o D^{i(r e}$, and $M y f 5^{C r e}$ mice. $A$, Representative images of lacZ staining of whole mount E15.5 embryos in MyoD ${ }^{i(r e+}$ lacZ $(n=2)$ and Myf5 ${ }^{\text {Cre }}+$ lacZ lines $(n=5)$. Scale bar, $2.5 \mathrm{~mm}$. $B$, Representative images of lacZ staining of spinal cord (top row) and skeletal muscle cross sections (bottom row) from P7 ChAT ${ }^{\text {ree+ }}$ lacZ, MyoD $D^{i c r e+}$ lacZ, and Myf5 ${ }^{\text {ree+ }}$ lacZ mice $\left(n=2\right.$ each). ${ }^{*}$ Indicates a DRG. Arrow indicates neurons in ventral horn of spinal cord. Scale bar, $500 \mu \mathrm{m}$. C, Representative images of ChAT/lacZ IHC in spinal cords from ChAT ${ }^{\text {(re + }}$ lacZ ( $n=3$ lacZ-positive), MyoD ${ }^{\text {icre+ }}$ lacZ ( $n=3$ lacZ-positive, 3 lacZ-negative) and Myf5 ${ }^{\text {re }}+$ lacZ mice ( $n=4$ lacZ-positive, 3 lacZ-negative examined). Punctate lacZ staining is evident in the cytoplasm and diffuse staining is visible in the nuclei of all motor neurons in $C h A T^{\text {Cre }}$ mice. LacZ staining is present in some, but not all motor neurons in Myf5 $5^{\text {Cre }}$ mice (indicated by arrows) and in other cells of the spinal cord (indicated by arrowheads). Scale bar, $50 \mu \mathrm{m}$. 


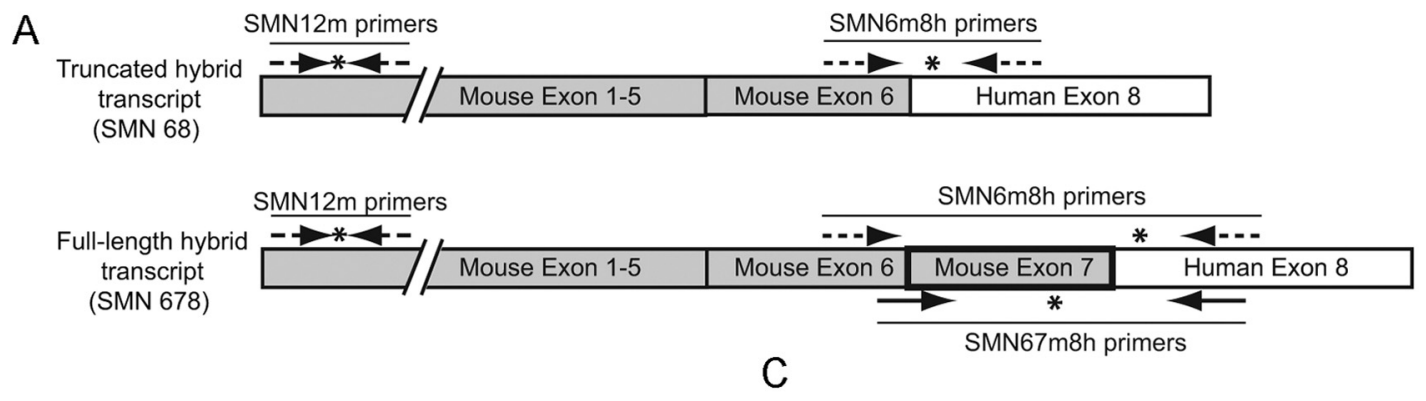

$\mathrm{B}$

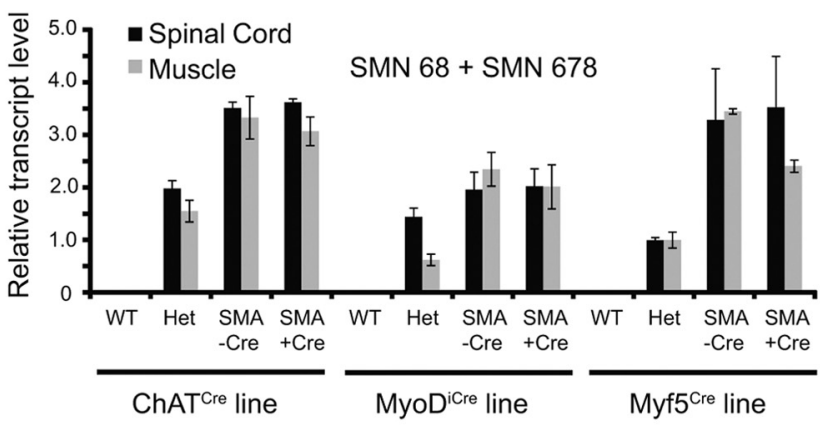

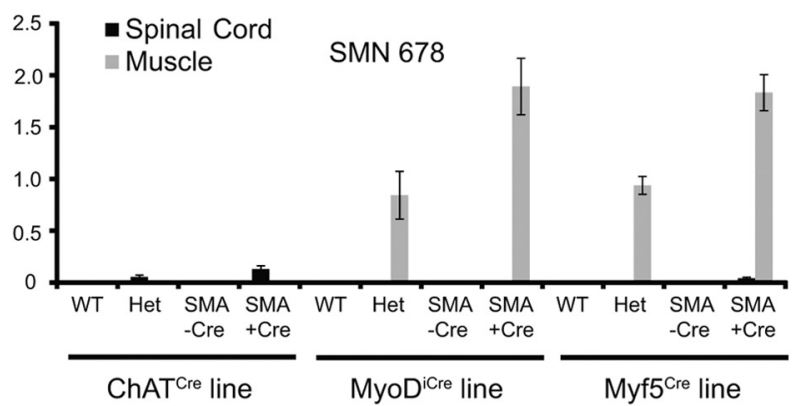

$\mathrm{D}$

ChAT ${ }^{\text {cre }}$ line

MyoDicre line
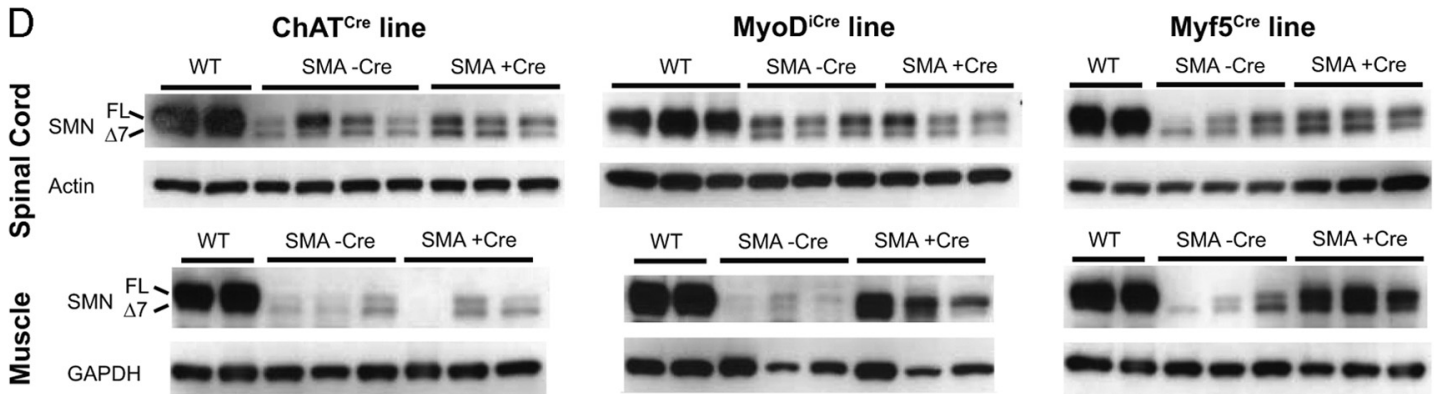

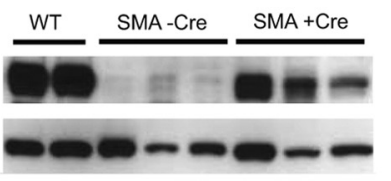

$\mathrm{F}$

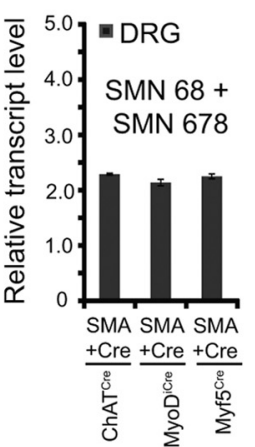

G

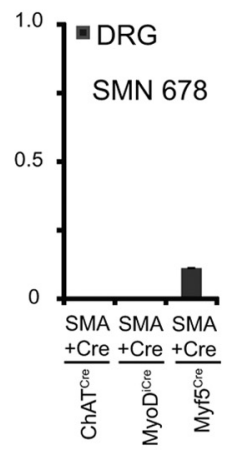

$\mathrm{H}$

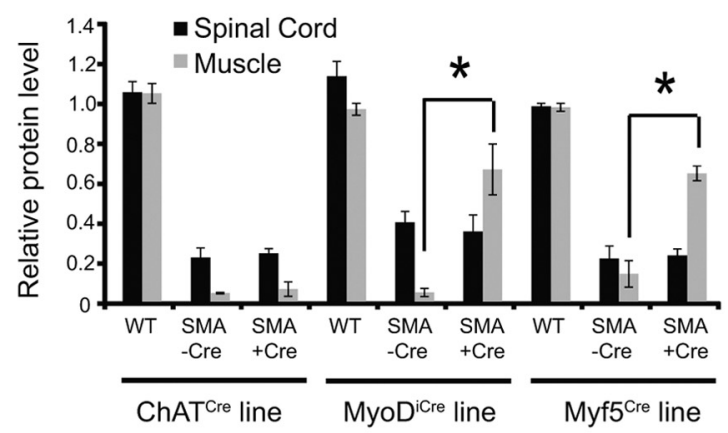

I
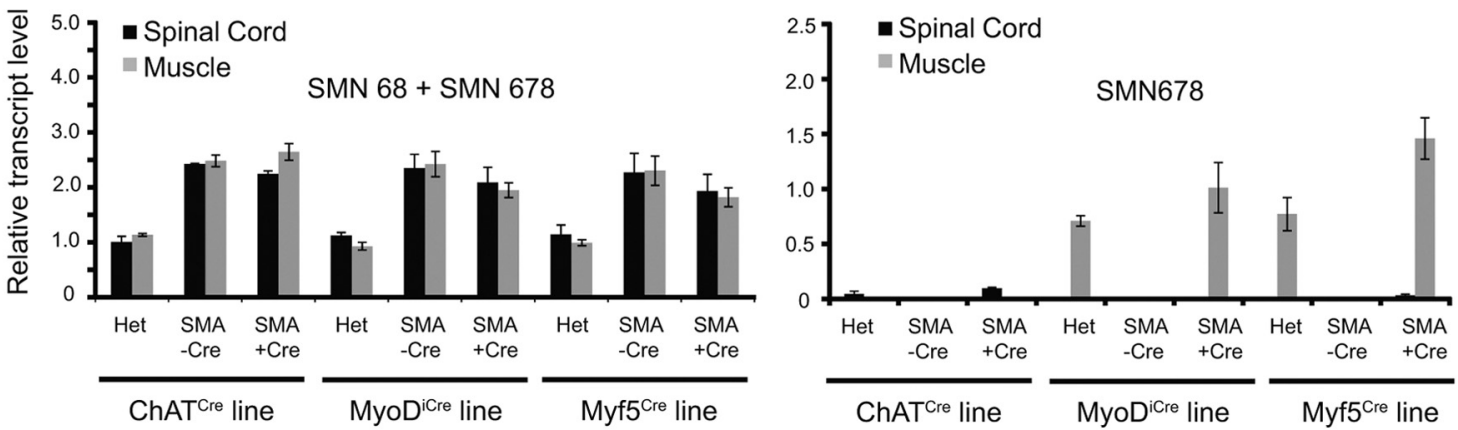

Figure 2. SMN is expressed in a tissue-specific manner in conditional SMA mice. $A$, Schematic demonstrating the exonic structures of the possible transcript products of the $S m n^{R e s}$ hybrid allele. In the absence of Cre recombinase, truncated hybrid transcript (SMN 68) is made containing upstream mouse Smn (exons 1-6), human SMN2 exon 8, and no exon 7 sequence. In the presence of Cre recombinase, a full-length hybrid transcript (SMN 678) containing mouse Smn exons 1-7 and human SMN2 exon 8 sequence may be made. The positions of qRT-PCR primers (Figure legend continues.) 
showed significant increases in full-length SMN protein expression in muscle by $491 \%$ and $362 \%$, respectively, but no changes were observed in spinal cords (Fig. $2 D, E$ ).

Given the appearance of lacZ expression in the DRG of $M y f 5^{\text {Cre }}$ reporter mice (Fig. $1 B$ ), we also examined all three lines of Cre+ SMA mice for SMN hybrid transcript expression levels in P10 lumbar DRGs (Fig. 2 F, G). SMN 678 was detectable only in $M y f 5^{\mathrm{Cre}+}$ SMA mice not in $\mathrm{ChAT}^{\mathrm{Cre}+}$ or $\mathrm{MyoD}^{i \mathrm{Cre}+} \mathrm{SMA}$ mice (Fig. 2F).

To verify expression of full-length hybrid SMN transcript at an early postnatal time point, we repeated the spinal cord and muscle qRT-PCR analysis on spinal cord and muscle tissues isolated at P2 (Fig. $2 H, I)$. These data indicate that SMN 678 hybrid transcripts are present in all three lines of mice at this early stage in the expected tissue-specific patterns.

\section{Increased SMN expression in motor neurons or muscles improves the disease phenotypes of SMA mice}

We next examined the phenotypic outcomes of SMA mice resulting from tissue-specific increases in full-length SMN expression (Fig. 3). Cre+ SMA mice showed increased survival compared with Cre - SMA mice in all 3 lines. Median survival increased from 15 to $23 \mathrm{~d}$ in ChAT $^{\text {Cre+ }}$ SMA mice (53\%, Log rank $p<0.0001)$, from 13 to $19 \mathrm{~d}$ in $M y o D^{i C r e+}$ SMA mice $(46 \%, \log$ rank $p<0.0001)$, and from 15 to $21 \mathrm{~d}$ in Myf5 ${ }^{\mathrm{Cre}+}$ SMA mice (40\%, Log rank $p<0.0004)$ (Fig. 3A). Weights were also significantly improved with $64.7 \%, 34.6 \%$, and $78.9 \%$ increases in maximal weights achieved in $\mathrm{ChAT}^{\mathrm{Cre}+}, \mathrm{MyoD}^{i \mathrm{Cre}+}$, and $M y f 5^{C r e+}$ SMA mice, respectively (Fig. $3 B$ ). Motor behavior assays showed reduced righting time latencies (Fig. $4 A$ ) in all three lines and increased tube test scores in muscle-rescued lines (Fig. $4 B$ ). Because ChAT ${ }^{\text {Cre+ }}$ SMA mice showed a partic-

\footnotetext{
$\leftarrow$

(Figure legend continued.) used are indicated with arrows indicating forward and reverse primers and asterisks indicating the positions of the probes. SMN6m8h primers detect both truncated and full-length hybrid transcripts, the SMN67m8h primers only detect full-length transcripts, and the SMN12m primers were used as an endogenous control. B, SMN6m8h primers detect hybrid transcripts in both spinal cord and muscle of P10 Cre + Het, $\mathrm{Cre}-\mathrm{SMA}$, and Cre + SMA mice, but not in WT mice. C, SMN67m8-h primers detect SMN 678 transcripts in spinal cord only in $\mathrm{ChAT}^{\text {(re }}{ }^{+}$and to a lesser extent, in $\mathrm{Myf5}^{\text {(re }+}$ Het and SMA mice. SMN 678 transcripts are expressed in muscle only in $M y O D^{i(r e++}$ and $M y f 5^{C r e+}$ Het and SMA mice ( $n=$ 3-8 per genotype). D, SMN protein levels were determined in spinal cord (top row) and muscle (bottom row) tissues of P10 WT, Cre - SMA, and Cre + SMA mice from each conditional SMA line. Both full-length (FL) and truncated $(\Delta 7)$ SMN protein isoforms are visible and are compared with the endogenous controls, actin or GAPDH. E, Densitometry analysis of FL SMN protein expression shows reduced FL SMN expression in Cre - SMA mice compared with WT mice in all three lines in both spinal cord and muscle. FL-SMN expression is significantly increased in the muscles of MyoD ${ }^{\text {iree+ }}$ and Myf5 ${ }^{\text {Cre+ }}$ SMA mice compared with Cre- SMA mice. ${ }^{*} p<0.01$. $\boldsymbol{F}$, SMN6m8h primers detect hybrid transcripts in the DRGs of all lines of Cre + SMA mice, but (G) SMN67m8 h primers detect SMN 678 transcripts only in DRGs of Myf5 ${ }^{\text {ree+ }}$ SMA mice, not ChAT ${ }^{\text {ree }}$ or MyoD ${ }^{\text {icre+ }}$ SMA mice ( $n=2-3$ per genotype). $\boldsymbol{H}$, SMN6m8-h primers and I SMN67m8h primers detect hybrid transcripts that are expressed in the appropriate tissue-specific patterns at early developmental time points. (All tissues isolated from mice at P2 except 2 of 3 Myf5 ${ }^{\text {cre }}+$ SMA mice, which were isolated at P5). $n=2-4$ per genotype.
}

ular improvement in motor behavior after P10 including the ability to rear and run, which was not seen in the $M y o D^{i C r e+}$ or $M y f 5^{C r e+}$ SMA mice, we measured features of ambulation in ChAT ${ }^{\text {Cre+ }}$ SMA and WT mice between P13-P23 (see Materials and Methods, Phenotypic assessment of mice). All ambulatory indices were similar in WT and ChAT $T^{\text {Cre+ }}$ SMA mice until $\sim$ P20 further indicating a marked improvement in motor function in ChAT ${ }^{\mathrm{Cre}+}$ SMA mice (Fig. 4C). Together these data indicate that increased SMN expression in motor neurons or muscle can partially ameliorate the SMA disease phenotype.

One pathological hallmark of SMA is motor neuron loss, with recent studies suggesting that particular motor neuron populations may be especially vulnerable to SMN deficiency. We have previously documented a progressive loss of motor neurons in the L1 segment ( $\sim 40 \%$ by P 4 and $60 \%$ by P13) of SMA mice, but little loss of lateral motor neurons in the L5 segment even at disease endstage (Mentis et al., 2011). Given these findings, we examined the total number of motor neurons in the vulnerable $\mathrm{L} 1$ segment at P10 (Fig. 5). In all lines of mice, there was an approximate $60 \%$ reduction in motor neuron number in Cre - SMA mice compared with WT mice (Fig. $5 A, B)$. ChAT ${ }^{\text {Cre+ }}$ SMA mice showed a $64 \%$ increase in MN number compared with Cre - SMA mice $(p=0.013)$, but no increase in motor neuron number was seen in $\mathrm{MyoD}^{i \mathrm{Cre}+}$ or $M y f 5^{C r e+}$ SMA mice (Fig. $5 B$ ). Another pathological feature of SMA mice is small muscles and myofibers (Kong et al., 2009; Lee et al., 2011). We examined the total muscle cross sectional area and myofiber diameter in P10 TA muscles (Fig. 6A, B) as we have previously demonstrated reduced myofiber diameter by $\mathrm{P9}$ in this muscle (Kong et al., 2009). In ChAT ${ }^{\mathrm{Cre}+} \mathrm{SMA}$ mice, myofiber diameter was modestly increased by $11 \%$ compared with Cre - SMA mice, but total muscle cross sectional area was not significantly increased (Fig. 6A,B). MyoD $D^{i C r e+}$ and $M y f 5^{C r e+}$ SMA mice showed a $38 \%$ and $67 \%$ increase in muscle area, respectively and both showed a $36 \%$ increase in myofiber diameter (Fig. 6A,B). 

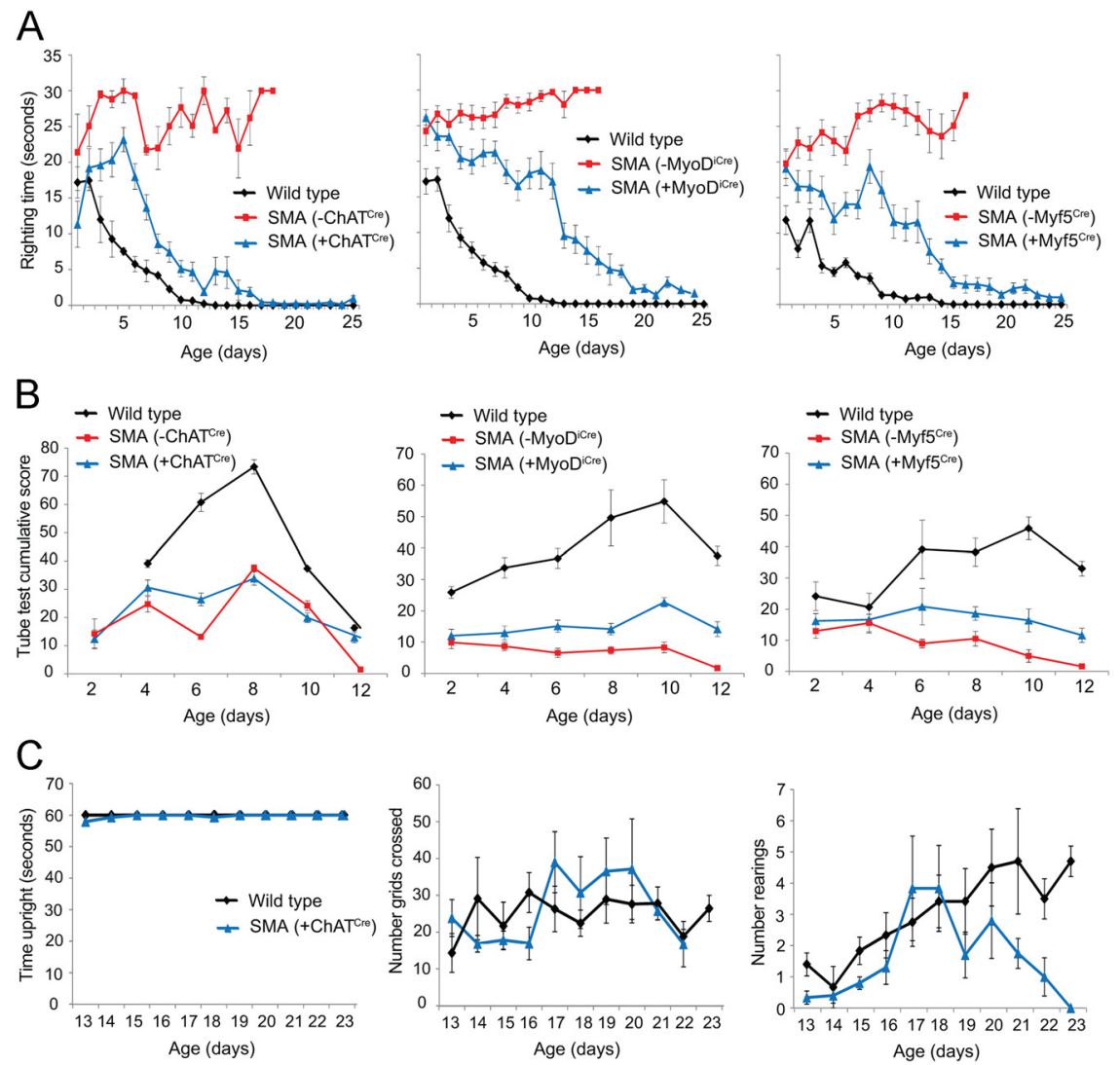

Figure 4. Motor behavior is improved in conditional SMA mice. $A$, Righting latency is reduced in Cre + SMA mice compared with Cre - SMA mice in all 3 lines of mice, $p<0.0001\left(C h A T^{\text {Cree }}: n=11\right.$ WT, 12 Cre - SMA, and 27 Cre + SMA, MyoD ${ }^{\text {icree }}: n=11$ WT, 12 Cre - SMA, and 18 Cre + SMA, Myf5 ${ }^{\text {Cree }}: n=10$ WT, 14 Cre - SMA, and 15 (re + SMA mice). $B$, Cumulative tube test scores are increased in $M y D^{i \text { ire }}+$ SMA mice compared with Cre - SMA mice, $p=0.01$ (ChAT ${ }^{\text {(re }}: n=5 \mathrm{WT}, 6 \mathrm{Cre}-\mathrm{SMA}$, and $13 \mathrm{Cre}+\mathrm{SMA}$, MyoD irre: $n=5$ WT, 6 Cre - SMA, and 7 Cre + SMA, Myf5 ${ }^{\text {(ree }}: n=5$ WT, 6 Cre - SMA, and 6 Cre + SMA mice). C, Ambulation indices including time upright (left), numbers of grids crossed (middle), and number of rearings (right) is equivalent between ChAT ${ }^{\text {(re }+}$ SMA mice and WT mice between P13 and P20 ( $n=3-6$ WT, 5- 6 Cre + SMA mice).

\section{Increased SMN expression in motor neurons, but not muscle, restores synaptic integrity}

We and others have previously shown that early stages of SMA disease pathogenesis are characterized by functional and structural abnormalities of NMJs. To determine whether these abnormalities arise from SMN deficiency in motor neurons alone or result from the combination of SMN deficiency at both presynaptic and postsynaptic sides of the NMJ, we examined the physiology of NMJs in the TA muscle as we have previously documented these NMJs to be fully innervated, but to have abnormalities of neuromuscular transmission (Kong et al., 2009). Specifically, SMA NMJs have reduced evoked endplate current (EPC) amplitudes (Kong et al., 2009), which are determined by both the number of synaptic vesicles released following nerve stimulation (quantal content) and the amplitude of the muscle response to the transmitter released from a single vesicle (quantal amplitude). In this study, we confirmed our previous observation that EPC amplitude was reduced by $\sim 60 \%(p<0.01)$ in CreSMA compared with WT mice in all three mouse lines (as WT and Cre-SMA values were highly similar across the three lines, they were combined) (Fig. $7 A, B)$. The reduction in EPC amplitude was due to a $40 \%$ reduction in quantal content $(p<0.01)$ and a $30 \%$ reduction in quantal amplitude $(p<0.01)$, as measured by MEPC amplitude (Fig. 7B). Previously, we also found that a reduction in the probability of synaptic vesicle release as shown by increased facilitation during repetitive stimulation was a likely contributor to the reduced quantal content in SMA NMJs (Kong et al., 2009). A similar increase in facilitation during repetitive stimulation was again observed in Cre - SMA compared with WT mice in the current study in all three lines of mice (Fig. 7B). Finally, we previously found an increase in MEPC and EPC time constants in SMA mice that was likely due to prolonged postsynaptic expression of embryonic acetylcholine receptors (AChRs) (Kong et al., 2009). In the three lines of conditional mice, there was a trend toward prolongation of the time constant in Cre-SMA compared with WT mice, but this increase was not statistically significant (data not shown).

We next examined whether increased expression of SMN in motor neurons or muscle rescued the abnormalities of neuromuscular transmission. Increased expression of SMN in motor neurons in ChAT $T^{\text {Cre+ }}$ SMA mice restored quantal content, MEPC (quantal) amplitude, EPC amplitude, and the facilitation response to repetitive stimulation to WT levels (Fig. $7 B)$. In contrast, $M y o D^{i C r e+}$ SMA mice showed no improvement in any parameter of NMJ function (Fig. 7B). Myf5 $5^{\mathrm{Cre}+}$ SMA mice had improvements of EPC amplitude and quantal content, but not of MEPC (quantal) amplitude or the response to repetitive stimulation (Fig. $7 B$ ).

Consistent with the restored function of NMJs in ChAT ${ }^{\text {Cre+ }}$ SMA mice, the NMJs in the TA muscle also showed improved structural characteristics with reduced NF accumulation in presynaptic terminals and increased postsynaptic endplate size (Fig. 7D) equivalent to WT levels. In contrast, $\mathrm{MyoD}^{i \mathrm{Cre}+}$ SMA mice showed no improvement in either parameter (Fig. 7D) and $\mathrm{Myf5}^{\mathrm{Cre+}}$ mice showed no change in NF accumulation, but did show increased endplate size (Fig. $7 D$ ). We also examined NMJs in the splenius capitis muscle as this muscle was recently shown to be susceptible to denervation in SMA mice (Ling et al., 2012). As expected, Cre- SMA mice showed a reduced number of highly innervated NMJs (as defined by $>75 \%$ occupancy of an endplate by the presynaptic terminal) compared with WT mice in all three lines (Fig. $7 C, D$ ). Both ChA ${ }^{C r e+}$ and $M y f 5^{C r e+}$ SMA mice showed an increased percentage of highly innervated and a decreased percentage of partially innervated NMJs (defined by 25-75\% occupancy of an endplate by the presynaptic terminal), whereas $M y o D^{i C r e+}$ SMA mice showed no change in innervation patterns (Fig. $7 D$ ). NF accumulation was also decreased in the splenius capitis muscle in ChAT ${ }^{\mathrm{Cre}+}$, but not $\mathrm{MyoD}^{\mathrm{iCre+}}$ or $\mathrm{Myf} 5^{\mathrm{Cre}}{ }^{+}$SMA mice (data not shown). Together these data indicate essentially complete restoration of NMJ structure and function in the motor neuronrescued ChAT $T^{\mathrm{Cre}+}$ SMA mice, a partial improvement in Myf5 $5^{\mathrm{Cre}+}$ SMA mice, and no change in the muscle-rescued $\mathrm{MyoD}^{i C r e+} \mathrm{SMA}$ mice.

In addition to abnormalities of NMJ synapses, recent studies have also highlighted disruptions of central motor neuron synaptic inputs in SMA mice suggesting that spinal circuitry discon- 
A

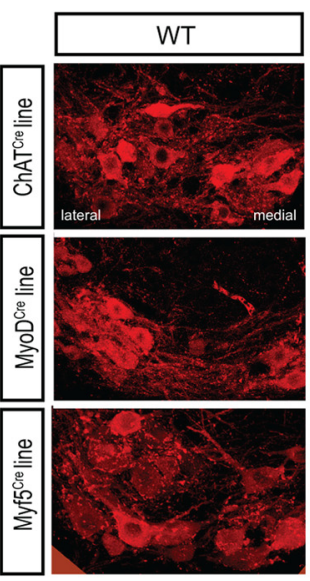

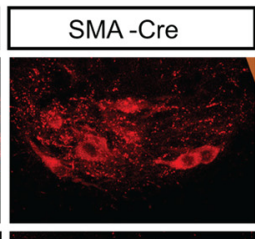
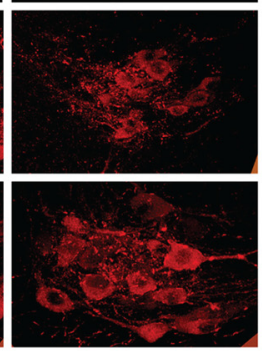

B
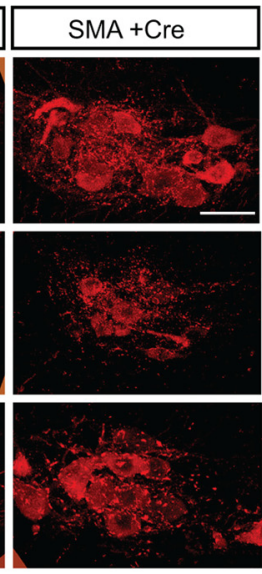

WT

SMA -Cre

SMA +Cre

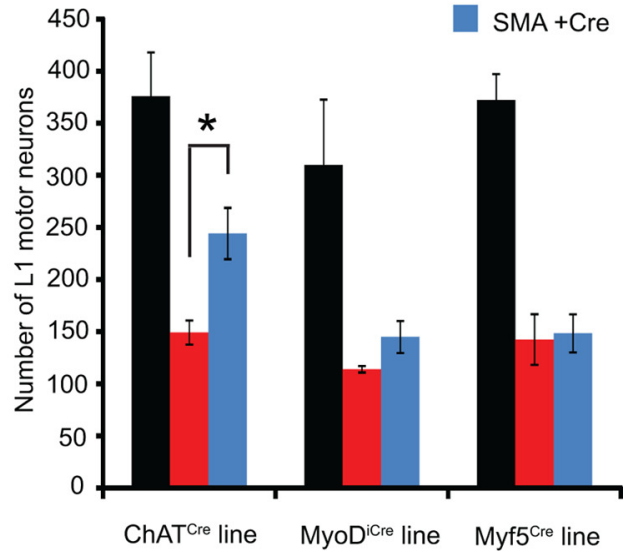

Figure 5. Increased SMN expression in motor neurons, but not muscle results in increased motor neuron number. $A$, Representative images of $L 1$ spinal cord ventral horn and ChAT-positive motor

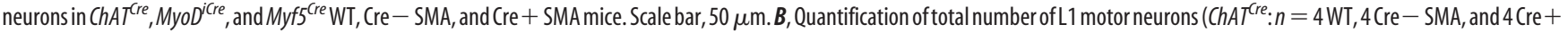
SMA, MyoD irre: $: n=4$ WT, 3 Cre - SMA, and 4 Cre + SMA, Myf5 ${ }^{\text {(re }}: n=4$ WT, 6 Cre - SMA, and 5 (re + SMA mice). ${ }^{*} p=0.01$.

A
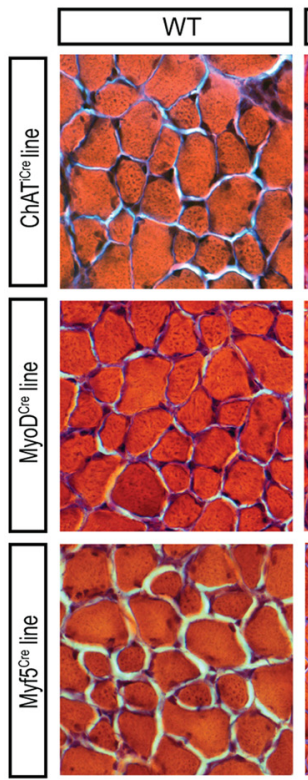

WT

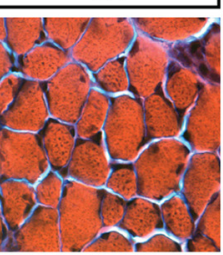

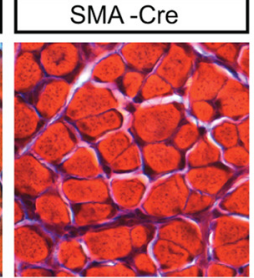
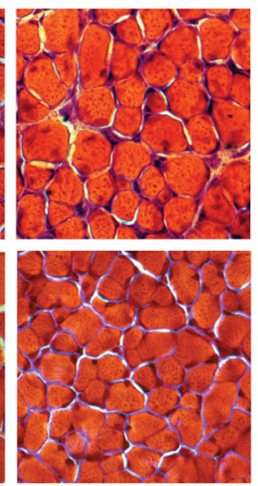

B
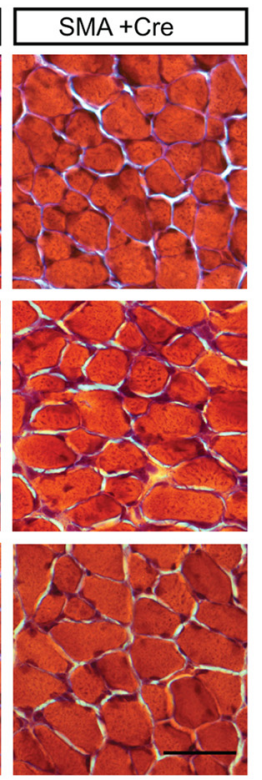
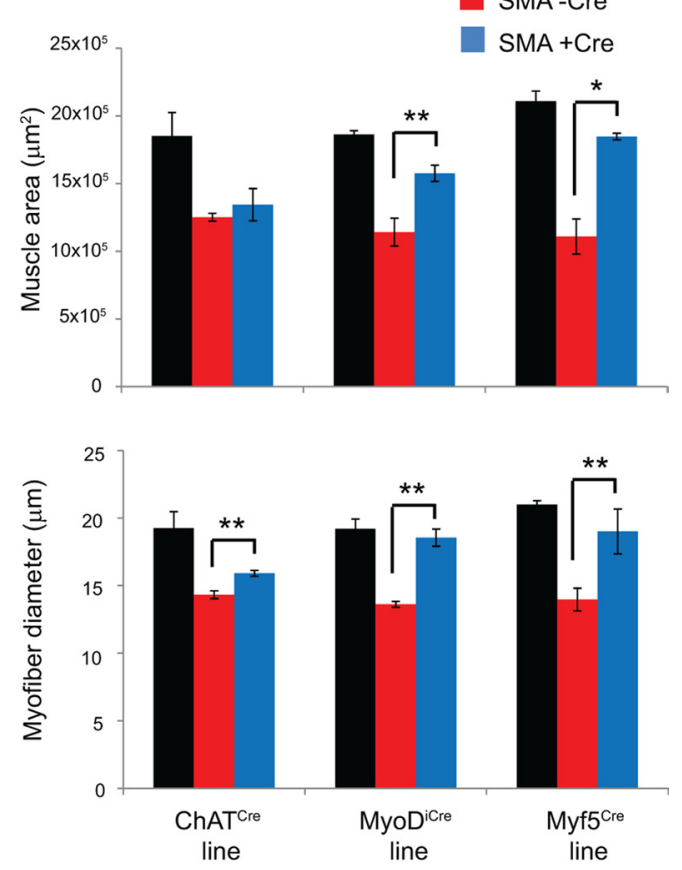

Figure 6. SMN expression in muscle restores myofiber size. $A$, Representative images of TA muscle cross sections from ChAT ${ }^{\text {cre }}, M y O D^{i(r e}$, and Myf5 ${ }^{\text {Cre }}$ WT, $C r e-S M A$, and Cre $+S M A$ mice. Scale

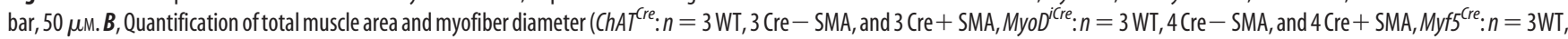
3 (re - SMA, and 3 (re + SMA mice). ${ }^{*} p=0.01,{ }^{* *} p=0.001$.

nections could exacerbate or even precipitate motor neuron dysfunction in SMA. To examine whether these synaptic disruptions are due to retrograde effects on motor neuron afferents from SMN-deficient motor neurons or due to intrinsic abnormalities of these motor neuron afferents themselves, we examined VGluT1+ sensorimotor synapses on L1 segment motor neuron somata in all three lines of SMA mice because we have previously shown these synapses to be structurally and functionally abnormal in SMA mice (Mentis et al., 2011). In all three lines of mice, we confirmed our previous observation that there was a $\sim 60-70 \%$ reduction of VGluT1 + synapses at P10 on L1 motor neuron cell bodies in Cre- SMA compared with WT mice (Fig. $8 A, B)$. ChA $T^{\text {Cre+ }}$ SMA mice showed a $124 \%$ increase in the number of VGluT1+ inputs compared with Cre- SMA mice, but there was no change in $M y o D^{i C r e+}$ or $M y f 5^{C r e+}$ SMA mice (Fig. $8 A, B)$. We further examined motor neuron somal synaptic inputs by electron microscopy (EM) in the ChAT ${ }^{\text {Cre }}$ line. We chose somata of approximately equivalent sizes (average perimeter length: $\mathrm{WT}=140.0 \pm 5.9 \mu \mathrm{m}, \mathrm{Cre}-\mathrm{SMA}=125.6 \pm 5.4 \mu \mathrm{m}$, and Cre+ $\mathrm{SMA}=124.0 \pm 10.7 \mu \mathrm{m})$. The total number of bou- 

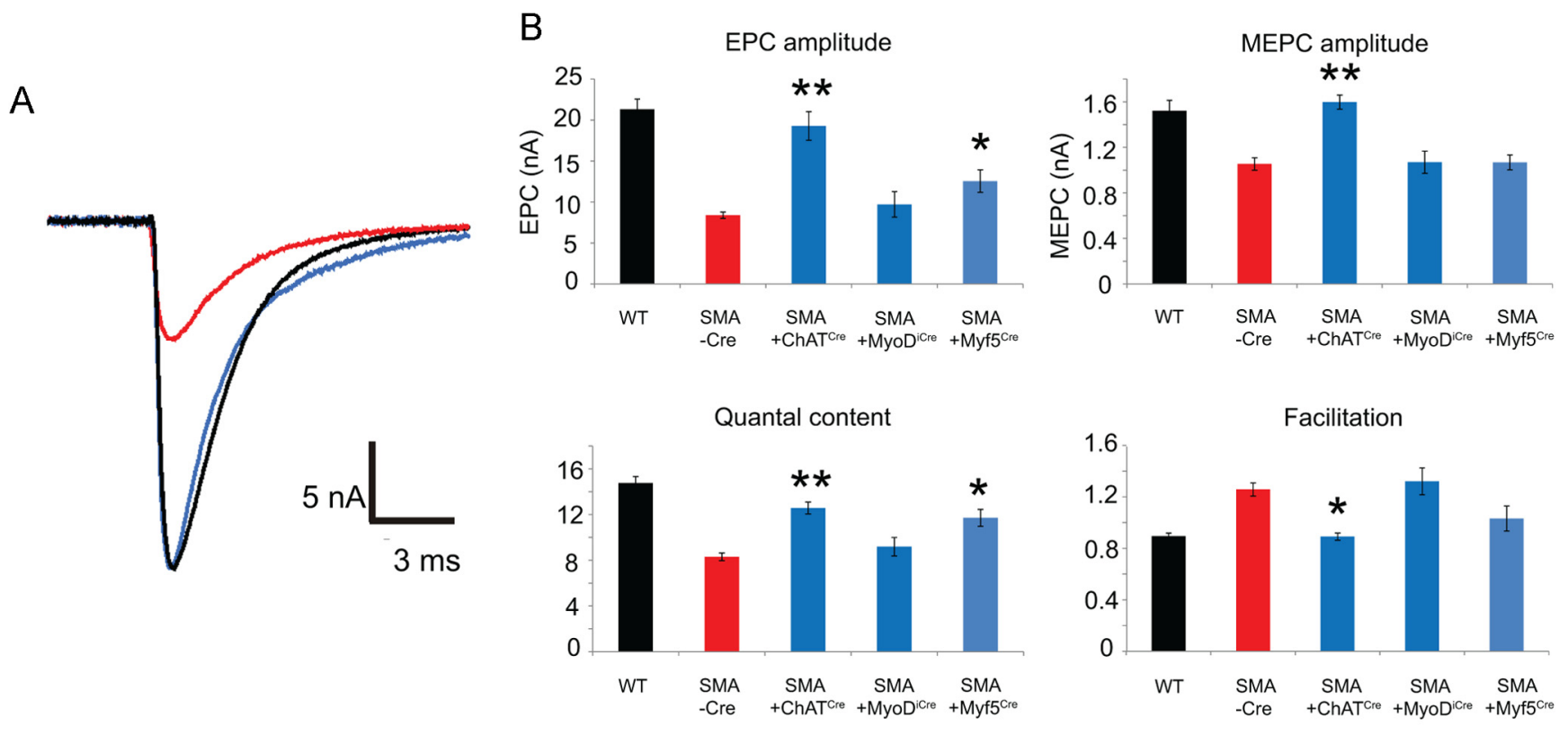

C
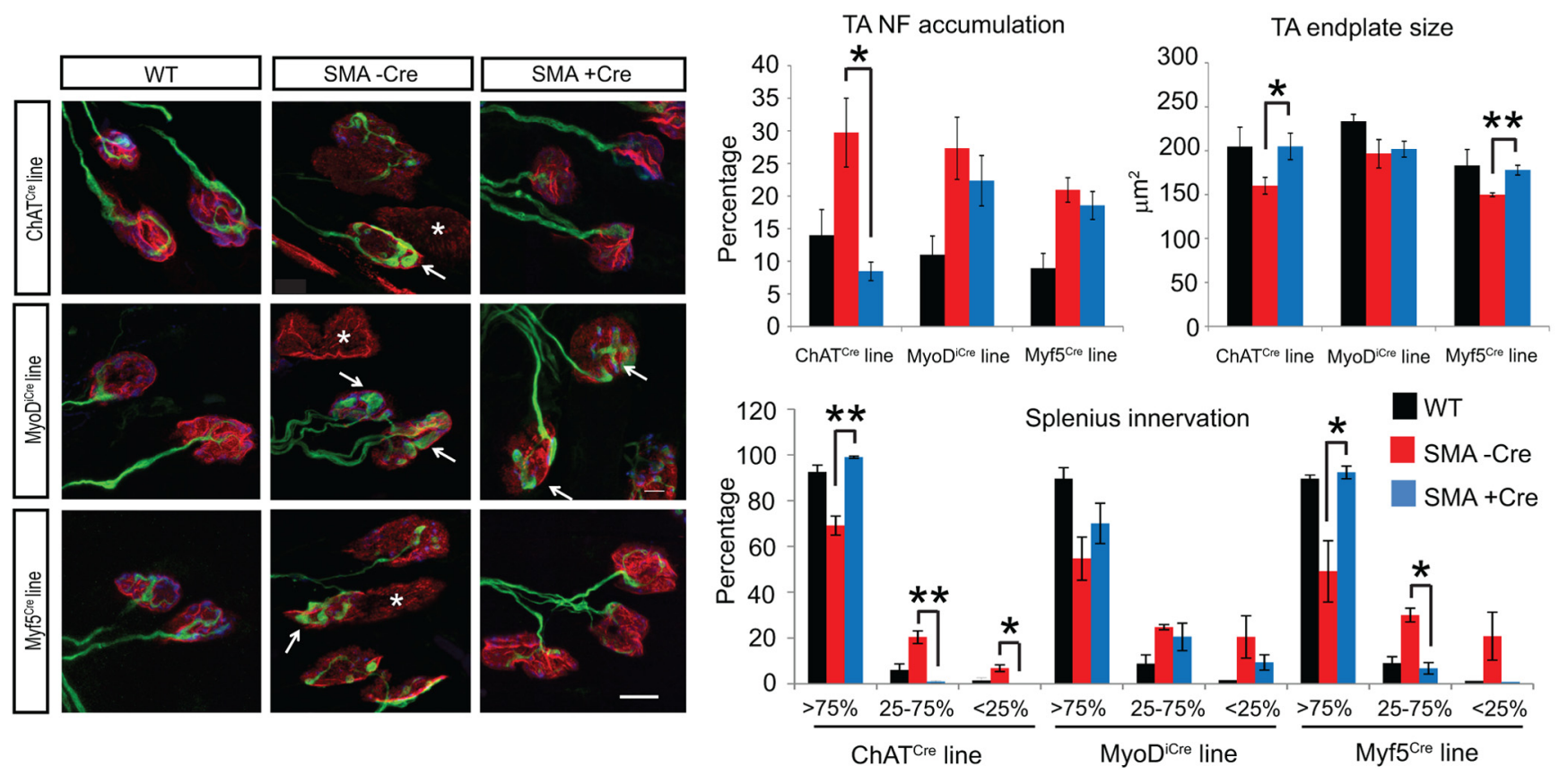

Figure 7. NMJ physiology and structure is improved by expression of SMN in motor neurons. $A$, Representative EPC traces from ChAT ${ }^{\text {(re }}$ WT (black), $(r e-S M A($ red), and Cre + SMA mice (blue).

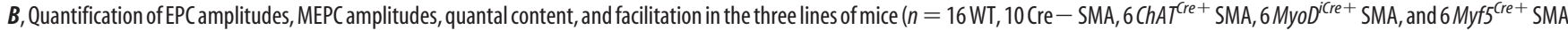
mice). ${ }^{*} p \leq 0.05,{ }^{* *} p<0.001$. C, Representative images of NMJs from the splenius capitis muscle in ChAT ${ }^{\text {Cre }}$, MyoD ${ }^{\text {icre }}$, and Myf5 ${ }^{\text {Cre }}$ WT, Cre - SMA, and Cre + SMA mice (red, $\alpha$-bungarotoxin; green, NF; blue, synaptophysin). Arrows indicate presynaptic terminals with NF accumulations. Asterisks indicate fully or partially denervated NMJs. Scale bar, $10 \mu \mathrm{m}$. $D, Q$ Quantification of TA muscle presynaptic terminal NF accumulation, TA muscle endplate size, and innervation status of the splenius capitis muscle in the 3 lines of mice (ChAT $T^{\mathrm{Cre} e}: n=4 \mathrm{WT}, 4 \mathrm{Cre}-\mathrm{SMA}, 4 \mathrm{Cre}+\mathrm{SMA}, M y D^{\mathrm{icre}}$ : $n=3$ WT, 4 Cre - SMA, and 4 (re + SMA, Myf5 ${ }^{\text {(re }}: n=3$ WT, 3 (re - SMA, 3 (re + SMA mice). ${ }^{*} p<0.05,{ }^{* *} p<0.001$.

tons present per soma was not statistically different between WT, Cre - SMA, and Cre + SMA mice $(\mathrm{WT}=42.1 \pm 4.5$, $\mathrm{Cre}-\mathrm{SMA}=31.7 \pm 4.1$, and Cre $+\mathrm{SMA}=43.1 \pm 6.2)$, but synapse number as defined by the presence of a bouton apposing a PSD was reduced by $40 \%$ in Cre - SMA compared with WT mice and was completely restored in ChAT $T^{\mathrm{Cre}+}$ SMA mice (Fig. 8C,D). PSD length showed a trend toward a decrease in Cre - and Cre + SMA mice compared with WT mice $(\mathrm{WT}=$ $0.41 \pm 0.03 \mu \mathrm{m}$, Cre $-\mathrm{SMA}=0.35 \pm 0.01 \mu \mathrm{m}$, and Cre + $\mathrm{SMA}=0.34 \pm 0.03 \mu \mathrm{m})$, but this did not reach statistical significance. We also observed a significant decrease in the density of synaptic vesicles in the presynaptic terminals of Cre-SMA motor neuron somal synapses, both when considering the density across the entire bouton as well as the density near the active zone, defined as vesicles within $100 \mathrm{~nm}$ of the PSD (Fig. $8 C, D$ ). The density of synaptic vesicles was restored in ChAT ${ }^{\mathrm{Cre}+}$ SMA mice (Fig. 8C,D). Together these data indicate that increased SMN expression in motor neurons not only restores NMJ synapses, but also prevents loss of central motor neuron synaptic input. 
A
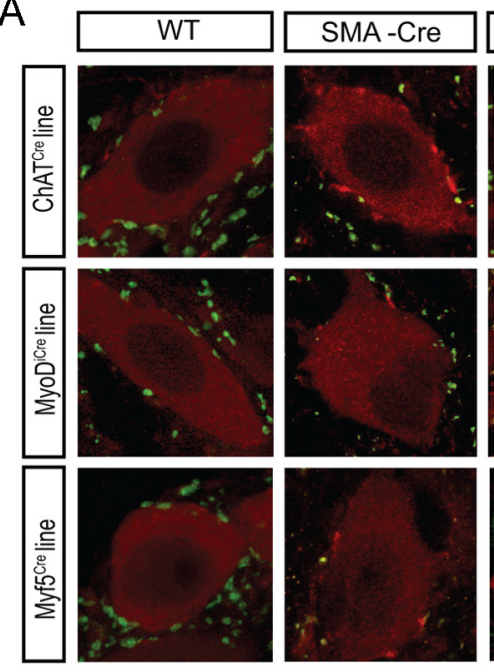

C

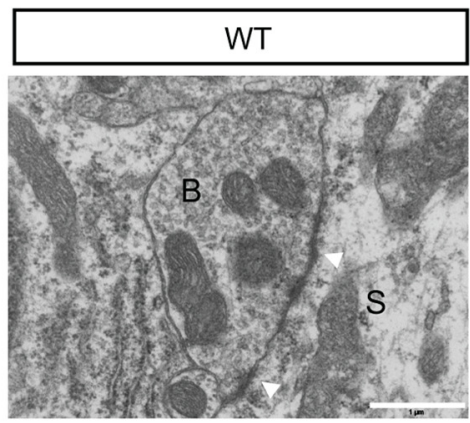

D

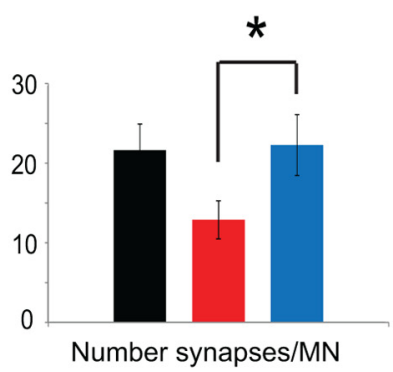

\section{SMA +Cre}

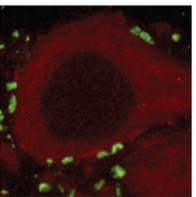

B
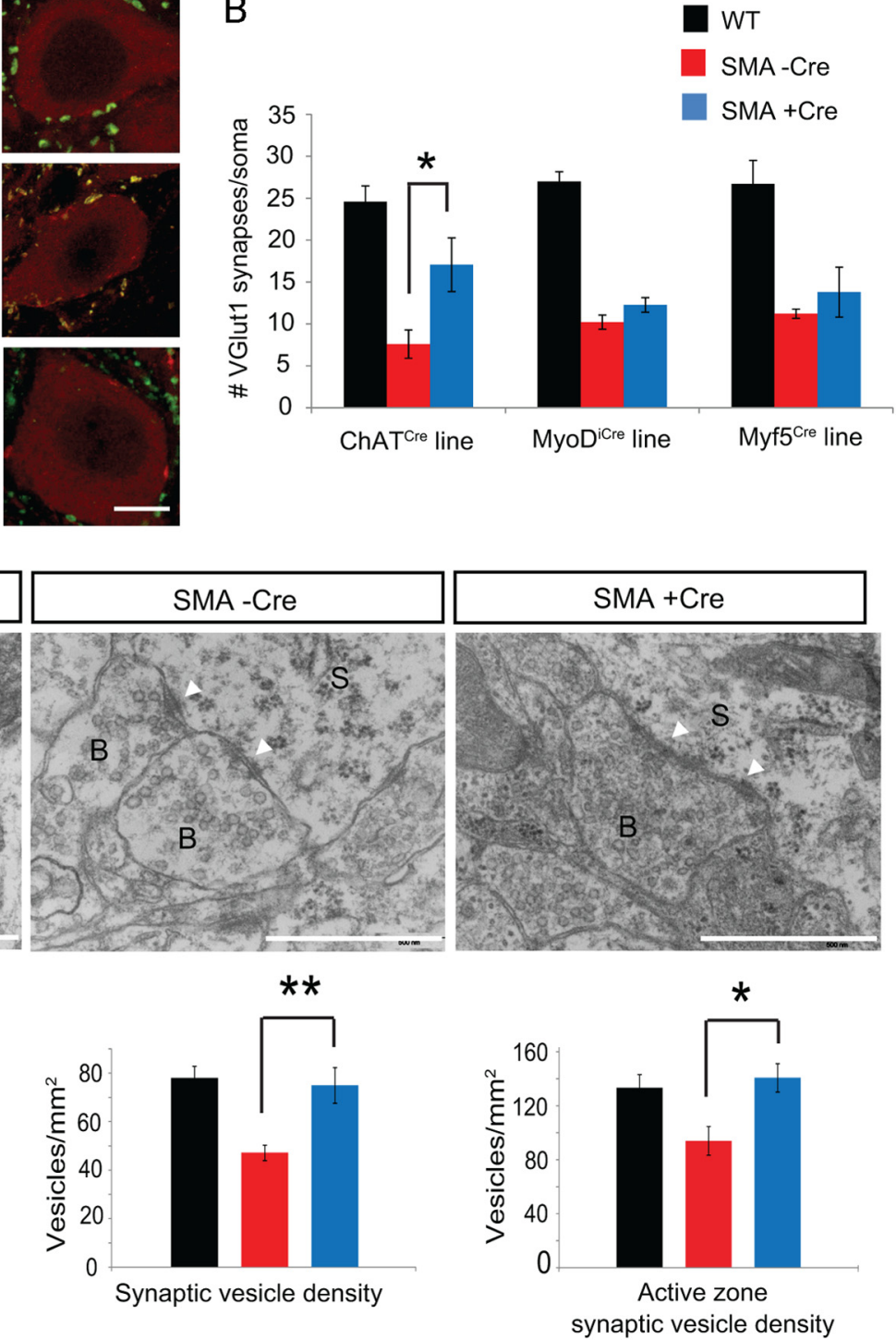

Figure 8. Motor neuron expression of SMN improves motor neuron somal synapses. $\boldsymbol{A}$, Representative images of VGluT1+ synapses on L1 motor neurons in $C h A T^{C r e}$, Myo $D^{i(r e}$, and $M y f 5^{C r e}$ WT, Cre - SMA, and Cre + SMA mice (red, ChAT; green, VGluT1). Scale bar, $10 \mu \mathrm{m}$. B, Quantification of VGluT1 + synapses in the three lines [ChAT ${ }^{C r}$ e. $n=3$ WT (17 neurons), 4 Cre - SMA (20 neurons), 3 Cre + SMA (22 neurons), MyoD ${ }^{i \text { rre }}: n=3$ WT (16 neurons), 4 Cre - SMA (17 neurons), and 3 Cre + SMA (21 neurons), Myf5 ${ }^{\text {Cre }}: n=3$ WT (14 neurons), 3 Cre - SMA (21 neurons) and 4 Cre + SMA

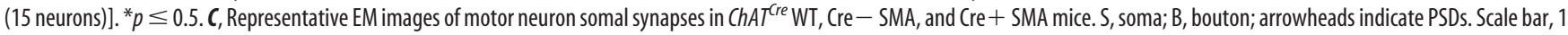
$\mu \mathrm{m} . \boldsymbol{D}$, Quantification of synapse number, PSD length, overall synaptic vesicle density, and active zone synaptic vesicle density in ChAT $T^{C r e}$ WT, Cre - SMA, and Cre + SMA mice (motor neuron\#: $n=$ 14 WT, 18 (re - SMA, and 14 (re + SMA). ${ }^{*} p<0.05,{ }^{* *} p<0.001$.

\section{Discussion}

Abnormalities of NMJ and central motor neuron synapses are principal cellular consequences of SMN deficiency during early, symptomatic stages of SMA. Here, we demonstrate that this synaptic connectivity is determined by the presence of SMN in motor neurons and is not influenced by SMN expression in muscle. SMN-deficient motor neurons thus determine synaptic integrity at the NMJ via a role restricted to the presynaptic terminal, but may influence central synapse connectivity via retrograde effects on somal synaptic inputs. Although selective SMN expression in muscle does not influence synaptic function and connectivity at either peripheral or central synapses, it can increase muscle growth.

Motor neurons and muscle interacting at NMJ synapses are dependent on each other for chemical, electrical, and trophic signals. Drosophila SMA models show NMJ abnormalities together with disorganized motor nerves and severe muscle atrophy (Chan et al., 2003; Rajendra et al., 2007; Chang et al., 2008) resulting from SMN deficiency at both presynaptic and postsynaptic sides of the NMJ (Chan et al., 2003; Chang et al., 2008). Recently, retrograde FGF signaling from muscle to nerve was demonstrated to rescue these NMJ defects (Sen et al., 2011), further illustrating the interdependency of motor nerve and muscle in these models.

SMA mice also have physiological and structural abnormalities of both presynaptic terminals and postsynaptic structures of the NMJ. Previous studies have reported reductions in quantal content (the number of vesicles released in response to nerve stimulation) at SMA NMJs that may be due to reduced probabil- 
ity of release (demonstrated by increased facilitation during repetitive stimulation) (Kariya et al., 2008; Murray et al., 2008; Kong et al., 2009; Ling et al., 2010; Ruiz et al., 2010). However, prolonged postsynaptic decay time constants and slowed maturation of the postsynaptic apparatus, including a delay in switching of acetylcholine receptor subunit expression, have also been described (Biondi et al., 2008; Kariya et al., 2008; Murray et al., 2008; Kong et al., 2009; Ling et al., 2010; Ruiz et al., 2010; Dachs et al., 2011).

In the current study, increased expression of SMN in motor neurons restored the presynaptic properties of quantal content and probability of synaptic vesicle release. In contrast, expression of SMN in muscle had no impact on these presynaptic functions. We also measured EPC and MEPC amplitudes (i.e., quantal amplitude) in this study and found them to be significantly reduced in SMA compared with WT mice. While our findings of reduced EPC and MEPC amplitude may seem to differ from other studies (Kariya et al., 2008; Murray et al., 2008; Ling et al., 2010; Ruiz et al., 2010), the likely explanation is our use of a two-electrode voltage-clamp technique rather than the more common single electrode measurement of synaptic voltage. This approach measures EPC and MEPC amplitudes without the confound of reduced muscle size, which increases muscle input resistance such that smaller amplitude EPCs and MEPCs of a given size could trigger endplate potentials (EPPs) and MEPPs of increased amplitude. Quantal amplitude is determined by the number of AChRs on the muscle fiber (a postsynaptic property) and the amount of transmitter contained in a vesicle (a presynaptic property). Thus rescue of MEPC (quantal) amplitude could be due to improvement of either a presynaptic or a postsynaptic defect in the NMJ. The most parsimonious explanation is that it is due to a presynaptic effect on the amount of transmitter contained in each synaptic vesicle, but we cannot rule out an anterograde transsynaptic trophic effect on the number of AChRs at the NMJ.

The restoration of NMJ function was accompanied by improved NMJ structure with reduced NF accumulation in presynaptic terminals, increased endplate size, and reduced denervation of the splenius capitis muscle. Our data indicate that the principal role of SMN at the NMJ is in presynaptic terminal function with little role in retrograde trophic support from muscle. These observations are consistent with the finding that selective reduction of SMN in motor neurons is sufficient to cause NMJ pathology (Park et al., 2010b). Interestingly, Myf5 $5^{\mathrm{Cre}+}$ SMA mice with low levels of increased SMN expression in motor neurons and high levels in muscle showed a partial improvement in NMJ physiology. This likely reflects the presence of SMN in motor neurons and indicates that even very low levels of SMN in motor neurons can impact NMJ function. Nonetheless, we cannot eliminate the possibility that low levels of SMN in motor neurons combined with high levels of SMN in muscle can together partially improve NMJ structure and function.

We also demonstrate that synaptic number and morphology of spinal motor neuron synaptic inputs are restored by increased expression of SMN in motor neurons, but not by expression in muscle. Previously, we demonstrated that VGluT1+ sensorimotor synapses are functionally impaired and that this is associated with their retraction before motor neuron death (Mentis et al., 2011). These abnormalities are associated with motor neuron hyperexcitability and are severe in L1 segment motor neurons (Mentis et al., 2011). Other motor neuron synapse types are also abnormal with preferential loss of excitatory versus inhibitory synapses (Ling et al., 2010). In the current study, the number of VGluT1+ somal synapses as well as the ultrastructural morphol- ogy of all somal synapses were significantly improved by increased expression of SMN in motor neurons indicating that these abnormalities are determined by retrograde effects of SMNdeficient motor neurons on presynaptic terminals. Increased expression of SMN in DRG neurons in $M y f 5^{\mathrm{Cre}+}$ SMA mice whose central projections form the VGluT1 + synapses did not prevent synaptic loss, further emphasizing the role of motor neurons in governing this process. Consistent with these results, during the revision of this manuscript Gogliotti et al. demonstrated that early restoration of SMN expression in motor neurons driven by the Hb-9 promoter resulted in increased VGLuT1+ motor neuron synapse number and corrected motor neuron hyperexcitability (Gogliotti et al., 2012). Ling et al. have suggested that this loss of motor neuron somal synapses represents a form of synaptic stripping (Ling et al., 2010), the active removal of central synapses by microglia. Synaptic stripping has been best described after nerve transaction, but it also occurs during motor neuron degenerative disease when it may be mediated in part by nitric oxide (Moreno-López et al., 2011).

Increased SMN in muscle resulted in complete rescue of myofiber growth accompanied by an increase in median survival and motor behavior. Interestingly, these benefits occurred independently of measurable improvement in NMJ and central synaptic structure. A previous study showed that increased expression of SMN controlled by the human skeletal actin (HSA) promoter did not result in a significant improvement in survival or motor behavior (Gavrilina et al., 2008). Although HSA is expressed in mature myofibers, it is not expressed in satellite cells or myoblasts. Satellite cells are critical for muscle growth during development and are also activated during muscle regeneration (Cerletti et al., 2008; Kang and Krauss, 2010). Several previous studies have suggested that SMN-deficient satellite cells and/or myoblasts may contribute to an impairment of SMA muscle development (Fidziańska et al., 1990; Braun et al., 1995; Nicole et al., 2003; Shafey et al., 2005; Dachs et al., 2011; Mutsaers et al., 2011). In the current study, we chose the MyoD and Myf5 promoters to drive Cre because these two proteins are expressed in essentially all muscle progenitors beginning in early embryogenesis, providing a means for widespread SMN expression in skeletal muscle. Our data support the conclusion that SMN plays a role in myofiber growth and development, although it is not yet clear whether embryonic or postnatal expression is responsible for rescue of the SMA muscle phenotype. Given that the ChAT${ }^{C r e+}$ SMA mice displayed only a partial increase in myofiber size, full restoration of muscle growth in severe forms of SMA may require targeting of SMN to muscle in addition to motor neurons. Further studies are needed to understand the specific molecular and cellular functions of SMN in muscle as previous attempts to activate muscle growth independent of SMN induction, including myostatin inhibition and insulin growth factor-1 treatment, have had limited success (Rose et al., 2009; Sumner et al., 2009; Bosch-Marcé et al., 2011; Rindt et al., 2012).

One question that arises from this study given the restoration of synaptic integrity in $C h A T^{\mathrm{Cre}+}$ SMA mice is why their survival is not more substantially increased. Widespread genetic restoration of SMN expression can markedly improve the disease phenotype in these mice if achieved within the first postnatal week (Le et al., 2011; Lutz et al., 2011). Gene therapy and antisense oligonucleotides strategies to increase SMN expression have also resulted in remarkable therapeutic effects (Foust et al., 2010; Passini et al., 2010; Dominguez et al., 2011; Passini et al., 2011; Porensky et al., 2012) with a recent study suggesting significantly enhanced efficacy with systemic compared with CNS-directed 
therapy (Hua et al., 2011). This later study highlights the unresolved question of which other tissue types contribute to SMA pathogenesis. Studies have increasingly reported abnormalities of other organ systems including the autonomic nervous system, heart, liver, and brain in SMA mice (Hua et al., 2011; Sleigh et al., 2011; Gogliotti et al., 2012). Further studies are needed to define the relative roles of these tissues in SMA pathogenesis and more importantly, their relevancy to human patients. Our data suggest that restoration of SMN in both motor neurons and muscle will be necessary for full functional recovery of the motor unit.

\section{References}

Avila AM, Burnett BG, Taye AA, Gabanella F, Knight MA, Hartenstein P, Cizman Z, Di Prospero NA, Pellizzoni L, Fischbeck KH, Sumner CJ (2007) Trichostatin A increases SMN expression and survival in a mouse model of spinal muscular atrophy. J Clin Invest 117:659-671.

Biondi O, Grondard C, Lécolle S, Deforges S, Pariset C, Lopes P, CifuentesDiaz C, Li H, della Gaspera B, Chanoine C, Charbonnier F (2008) Exercise-induced activation of NMDA receptor promotes motor unit development and survival in a type 2 spinal muscular atrophy model mouse. J Neurosci 28:953-962.

Bosch-Marcé M, Wee CD, Martinez TL, Lipkes CE, Choe DW, Kong L, Van Meerbeke JP, Musarò A, Sumner CJ (2011) Increased IGF-1 in muscle modulates the phenotype of severe SMA mice. Hum Mol Genet 20:1844-1853.

Braun S, Croizat B, Lagrange MC, Warter JM, Poindron P (1995) Constitutive muscular abnormalities in culture in spinal muscular atrophy. Lancet 345:694-695.

Burghes AH, Beattie CE (2009) Spinal muscular atrophy: why do low levels of survival motor neuron protein make motor neurons sick? Nat Rev Neurosci 10:597-609.

Cerletti M, Shadrach JL, Jurga S, Sherwood R, Wagers AJ (2008) Regulation and function of skeletal muscle stem cells. Cold Spring Harb Symp Quant Biol 73:317-322.

Chan YB, Miguel-Aliaga I, Franks C, Thomas N, Trülzsch B, Sattelle DB, Davies KE, van den Heuvel M (2003) Neuromuscular defects in a Drosophila survival motor neuron gene mutant. Hum Mol Genet 12:1367-1376.

Chang HC, Dimlich DN, Yokokura T, Mukherjee A, Kankel MW, Sen A, Sridhar V, Fulga TA, Hart AC, Van Vactor D, Artavanis-Tsakonas S (2008) Modeling spinal muscular atrophy in Drosophila. PLoS ONE 3:e3209.

Crawford TO (2003) Spinal muscular atrophies. In: Neuromuscular disorders of infancy, childhood and adolescence: a clinician's approach (Jones H, Vivo DD, Darras B, eds), pp 145-166. Philadelphia: Butterworth Heinemann.

Dachs E, Hereu M, Piedrafita L, Casanovas A, Calderó J, Esquerda JE (2011) Defective neuromuscular junction organization and postnatal myogenesis in mice with severe spinal muscular atrophy. J Neuropathol Exp Neurol 70:444-461.

Dominguez E, Marais T, Chatauret N, Benkhelifa-Ziyyat S, Duque S, Ravassard P, Carcenac R, Astord S, Pereira de Moura A, Voit T, Barkats M (2011) Intravenous scAAV9 delivery of a codon-optimized SMN1 sequence rescues SMA mice. Hum Mol Genet 20:681-693.

Dubowitz V (1995) Muscle disorders in childhood, Ed 2. Philadelphia: WB Saunders.

El-Khodor BF, Edgar N, Chen A, Winberg ML, Joyce C, Brunner D, SuárezFariñas M, Heyes MP (2008) Identification of a battery of tests for drug candidate evaluation in the SMNDelta7 neonate model of spinal muscular atrophy. Exp Neurol 212:29-43.

Feldkötter M, Schwarzer V, Wirth R, Wienker TF, Wirth B (2002) Quantitative analyses of SMN1 and SMN2 based on real-time lightCycler PCR: fast and highly reliable carrier testing and prediction of severity of spinal muscular atrophy. Am J Hum Genet 70:358-368.

Fidziańska A, Goebel HH, Warlo I (1990) Acute infantile spinal muscular atrophy. Muscle apoptosis as a proposed pathogenetic mechanism. Brain 113:433-445.

Foust KD, Wang X, McGovern VL, Braun L, Bevan AK, Haidet AM, Le TT, Morales PR, Rich MM, Burghes AH, Kaspar BK (2010) Rescue of the spinal muscular atrophy phenotype in a mouse model by early postnatal delivery of SMN. Nat Biotechnol 28:271-274.
Gavrilina TO, McGovern VL, Workman E, Crawford TO, Gogliotti RG, DiDonato CJ, Monani UR, Morris GE, Burghes AH (2008) Neuronal SMN expression corrects spinal muscular atrophy in severe SMA mice while muscle-specific SMN expression has no phenotypic effect. Hum Mol Genet 17:1063-1075.

Gensch N, Borchardt T, Schneider A, Riethmacher D, Braun T (2008) Different autonomous myogenic cell populations revealed by ablation of Myf5-expressing cells during mouse embryogenesis. Development 135:1597-1604.

Gogliotti RG, Quinlan KA, Barlow CB, Heier CR, Heckman CJ, Didonato CJ (2012) Motor neuron rescue in spinal muscular atrophy mice demonstrates that sensory-motor defects are a consequence, not a cause, of motor neuron dysfunction. J Neurosci 32:3818-3829.

Heier CR, Satta R, Lutz C, DiDonato CJ (2010) Arrhythmia and cardiac defects are a feature of spinal muscular atrophy model mice. Hum Mol Genet 19:3906-3918.

Hua Y, Sahashi K, Rigo F, Hung G, Horev G, Bennett CF, Krainer AR (2011) Peripheral SMN restoration is essential for long-term rescue of a severe spinal muscular atrophy mouse model. Nature 478:123-126.

Kang JS, Krauss RS (2010) Muscle stem cells in developmental and regenerative myogenesis. Curr Opin Clin Nutr Metab Care 13:243-248.

Kanisicak O, Mendez JJ, Yamamoto S, Yamamoto M, Goldhamer DJ (2009) Progenitors of skeletal muscle satellite cells express the muscle determination gene, MyoD. Dev Biol 332:131-141.

Kariya S, Park GH, Maeno-Hikichi Y, Leykekhman O, Lutz C, Arkovitz MS, Landmesser LT, Monani UR (2008) Reduced SMN protein impairs maturation of the neuromuscular junctions in mouse models of spinal muscular atrophy. Hum Mol Genet 17:2552-2569.

Kong L, Wang X, Choe DW, Polley M, Burnett BG, Bosch-Marcé M, Griffin JW, Rich MM, Sumner CJ (2009) Impaired synaptic vesicle release and immaturity of neuromuscular junctions in spinal muscular atrophy mice. J Neurosci 29:842-851.

Le TT, Pham LT, Butchbach ME, Zhang HL, Monani UR, Coovert DD, Gavrilina TO, Xing L, Bassell GJ, Burghes AH (2005) SMNDelta7, the major product of the centromeric survival motor neuron (SMN2) gene, extends survival in mice with spinal muscular atrophy and associates with fulllength SMN. Hum Mol Genet 14:845-857.

Le TT, McGovern VL, Alwine IE, Wang X, Massoni-Laporte A, Rich MM, Burghes AH (2011) Temporal requirement for high SMN expression in SMA mice. Hum Mol Genet 20:3578-3591.

Lee YI, Mikesh M, Smith I, Rimer M, Thompson W (2011) Muscles in a mouse model of spinal muscular atrophy show profound defects in neuromuscular development even in the absence of failure in neuromuscular transmission or loss of motor neurons. Dev Biol 356:432-444.

Lefebvre S, Bürglen L, Reboullet S, Clermont O, Burlet P, Viollet L, Benichou B, Cruaud C, Millasseau P, Zeviani M, Le Paslier D, Frézal J, Cohen D, Weissenbach J, Munnich A, Melki J (1995) Identification and characterization of a spinal muscular atrophy-determining gene. Cell 80:155-165.

Ling KK, Lin MY, Zingg B, Feng Z, Ko CP (2010) Synaptic defects in the spinal and neuromuscular circuitry in a mouse model of spinal muscular atrophy. PLoS ONE 5:e15457.

Ling KK, Gibbs RM, Feng Z, Ko CP (2012) Severe neuromuscular denervation of clinically relevant muscles in a mouse model of spinal muscular atrophy. Hum Mol Genet 21:185-195.

Lönnerberg P, Lendahl U, Funakoshi H, Arhlund-Richter L, Persson H, Ibáñez CF (1995) Regulatory region in choline acetyltransferase gene directs developmental and tissue-specific expression in transgenic mice. Proc Natl Acad Sci U S A 92:4046-4050.

Lorson CL, Strasswimmer J, Yao JM, Baleja JD, Hahnen E, Wirth B, Le T, Burghes AH, Androphy EJ (1998) SMN oligomerization defect correlates with spinal muscular atrophy severity. Nat Genet 19:63-66.

Lorson CL, Hahnen E, Androphy EJ, Wirth B (1999) A single nucleotide in the SMN gene regulates splicing and is responsible for spinal muscular atrophy. Proc Natl Acad Sci U S A 96:6307-6311.

Lutz CM, Kariya S, Patruni S, Osborne MA, Liu D, Henderson CE, Li DK, Pellizzoni L, Rojas J, Valenzuela DM, Murphy AJ, Winberg ML, Monani UR (2011) Postsymptomatic restoration of SMN rescues the disease phenotype in a mouse model of severe spinal muscular atrophy. J Clin Invest 121:3029-3041.

Mentis GZ, Blivis D, Liu W, Drobac E, Crowder ME, Kong L, Alvarez FJ, Sumner CJ, O’Donovan MJ (2011) Early functional impairment of 
sensory-motor connectivity in a mouse model of spinal muscular atrophy. Neuron 69:453-467.

Monani UR, Lorson CL, Parsons DW, Prior TW, Androphy EJ, Burghes AH, McPherson JD (1999) A single nucleotide difference that alters splicing patterns distinguishes the SMA gene SMN1 from the copy gene SMN2. Hum Mol Genet 8:1177-1183.

Moreno-López B, Sunico CR, González-Forero D (2011) NO orchestrates the loss of synaptic boutons from adult "sick" motoneurons: modeling a molecular mechanism. Mol Neurobiol 43:41-66.

Murray LM, Comley LH, Thomson D, Parkinson N, Talbot K, Gillingwater TH (2008) Selective vulnerability of motor neurons and dissociation of pre- and post-synaptic pathology at the neuromuscular junction in mouse models of spinal muscular atrophy. Hum Mol Genet 17:949-962.

Mutsaers CA, Wishart TM, Lamont DJ, Riessland M, Schreml J, Comley LH, Murray LM, Parson SH, Lochmüller H, Wirth B, Talbot K, Gillingwater TH (2011) Reversible molecular pathology of skeletal muscle in spinal muscular atrophy. Hum Mol Genet 20:4334-4344.

Nicole S, Desforges B, Millet G, Lesbordes J, Cifuentes-Diaz C, Vertes D, Cao ML, De Backer F, Languille L, Roblot N, Joshi V, Gillis JM, Melki J (2003) Intact satellite cells lead to remarkable protection against Smn gene defect in differentiated skeletal muscle. J Cell Biol 161:571-582.

Ott MO, Bober E, Lyons G, Arnold H, Buckingham M (1991) Early expression of the myogenic regulatory gene, myf-5, in precursor cells of skeletal muscle in the mouse embryo. Development 111:1097-1107.

Park GH, Kariya S, Monani UR (2010a) Spinal muscular atrophy: new and emerging insights from model mice. Curr Neurol Neurosci Rep 10:108-117.

Park GH, Maeno-Hikichi Y, Awano T, Landmesser LT, Monani UR (2010b) Reduced survival of motor neuron (SMN) protein in motor neuronal progenitors functions cell autonomously to cause spinal muscular atrophy in model mice expressing the human centromeric (SMN2) gene. J Neurosci 30:12005-12019.

Passini MA, Bu J, Roskelley EM, Richards AM, Sardi SP, O'Riordan CR, Klinger KW, Shihabuddin LS, Cheng SH (2010) CNS-targeted gene therapy improves survival and motor function in a mouse model of spinal muscular atrophy. J Clin Invest 120:1253-1264.

Passini MA, Bu J, Richards AM, Kinnecom C, Sardi SP, Stanek LM, Hua Y, Rigo F, Matson J, Hung G, Kaye EM, Shihabuddin LS, Krainer AR, Bennett CF, Cheng SH (2011) Antisense oligonucleotides delivered to the mouse CNS ameliorate symptoms of severe spinal muscular atrophy. Sci Transl Med 3:72ra18.
Phelps PE, Barber RP, Vaughn JE (1991) Embryonic development of choline acetyltransferase in thoracic spinal motor neurons: somatic and autonomic neurons may be derived from a common cellular group. J Comp Neurol 307:77-86.

Porensky PN, Mitrpant C, McGovern VL, Bevan AK, Foust KD, Kaspar BK, Wilton SD, Burghes AH (2012) A single administration of morpholino antisense oligomer rescues spinal muscular atrophy in mouse. Hum Mol Genet 21:1625-1638.

Rajendra TK, Gonsalvez GB, Walker MP, Shpargel KB, Salz HK, Matera AG (2007) A Drosophila melanogaster model of spinal muscular atrophy reveals a function for SMN in striated muscle. J Cell Biol 176:831-841.

Rindt H, Buckley DM, Vale SM, Krogman M, Rose FF Jr, Garcia ML, Lorson CL (2012) Transgenic inactivation of murine myostatin does not decrease the severity of disease in a model of spinal muscular atrophy. Neuromuscul Disord 22:277-285.

Rose FF Jr, Mattis VB, Rindt H, Lorson CL (2009) Delivery of recombinant follistatin lessens disease severity in a mouse model of spinal muscular atrophy. Hum Mol Genet 18:997-1005.

Ruiz R, Casañas JJ, Torres-Benito L, Cano R, Tabares L (2010) Altered intracellular $\mathrm{Ca} 2+$ homeostasis in nerve terminals of severe spinal muscular atrophy mice. J Neurosci 30:849-857.

Sen A, Yokokura T, Kankel MW, Dimlich DN, Manent J, Sanyal S, ArtavanisTsakonas S (2011) Modeling spinal muscular atrophy in Drosophila links Smn to FGF signaling. J Cell Biol 192:481-495.

Shafey D, Côté PD, Kothary R (2005) Hypomorphic Smn knockdown $\mathrm{C} 2 \mathrm{C} 12$ myoblasts reveal intrinsic defects in myoblast fusion and myotube morphology. Exp Cell Res 311:49-61.

Sleigh JN, Gillingwater TH, Talbot K (2011) The contribution of mouse models to understanding the pathogenesis of spinal muscular atrophy. Dis Model Mech 4:457-467.

Soriano P (1999) Generalized lacZ expression with the ROSA26 Cre reporter strain. Nat Genet 21:70-71.

Sumner CJ, Wee CD, Warsing LC, Choe DW, Ng AS, Lutz C, Wagner KR (2009) Inhibition of myostatin does not ameliorate disease features of severe spinal muscular atrophy mice. Hum Mol Genet 18:3145-3152.

Tallquist MD, Weismann KE, Hellström M, Soriano P (2000) Early myotome specification regulates PDGFA expression and axial skeleton development. Development 127:5059-5070.

Yamamoto M, Shook NA, Kanisicak O, Yamamoto S, Wosczyna MN, Camp JR, Goldhamer DJ (2009) A multifunctional reporter mouse line for Cre- and FLP-dependent lineage analysis. Genesis 47:107-114. 